\title{
Influência do Índice de Massa Corporal na Sobrevida de Mulheres com Diferentes Subtipos de Câncer de Mama: uma Revisão Integrativa
}

doi: https://doi.org/10.32635/2176-9745.RBC.2019v65n2.373

\author{
Influence of Body Mass Index on Survival of Women with Different Subtypes of Breast Cancer: an Integrative Review \\ Influencia del Índice de Masa Corporal en la Supervivencia de las Mujeres con Diferentes Subtipos de Cáncer de Mama: \\ una Revisión Integrativa
}

Rosilene de Lima Pinheiro'; Gina Torres Rego Monteiro²

Resumo

Introduçáo: A obesidade é considerada fator prognóstico negativo para mulheres com câncer de mama; entretanto, sua influência sobre o curso da doença pode ser diferenciada nos subtipos moleculares. Objetivo: Analisar a influência do índice de massa corporal (IMC) na sobrevida de mulheres com câncer de mama segundo o subtipo molecular. Método: Realizada revisão integrativa de literatura utilizando estratégia PICOS para formulação da pesquisa, identificação de palavras-chave e definição dos critérios de elegibilidade. Estudos que analisaram a influência do IMC na sobrevida de mulheres com câncer de mama, por subtipo tumoral, utilizando risco proporcional de COX e/ou Kaplan-Meier, publicados até junho de 2018, foram identificados nas bases PubMed, BVS, Scopus e Web of Science. Resultados: Foram selecionados 23 estudos entre 446 identificados. Mulheres com tumores do tipo triplo-negativo nas maiores categorias de IMC exibiram pior sobrevida em quatro dos 17 estudos incluindo esse subtipo. Nos casos de tumores luminal, IMC elevado foi fator prognóstico negativo em sete entre 11 estudos. Para HER2 (receptor tipo 2 do fator de crescimento epidérmico humano) superexpresso, houve pior sobrevida quando IMC elevado em dois dos seis estudos. Entre os HER2 positivos, independente do status hormonal, observou-se pior sobrevida para mulheres com maiores IMC em dois dos cinco estudos. Conclusáo: O efeito do IMC na sobrevida de mulheres com câncer de mama parece ser diferenciado de acordo com o subtipo tumoral, sendo seu efeito, aparentemente, maior naquelas com tumores luminais. Palavras-chave: Neoplasias da Mama/classificação; Índice de Massa Corporal; Análise de Sobrevida.

\begin{abstract}
Introduction: Obesity is considered a negative prognostic factor for women with breast cancer, however, its influence on the course of the disease can be differentiated in molecular subtypes. Objective: To analyze the influence of the body mass index (BMI) on the survival of women with breast cancer according to the molecular subtype. Method: Integrative review using PICOS strategy for the design of the study, identification of keywords and definition of eligibility criteria. Studies that analyzed the influence of BMI on the survival of women with breast cancer, by tumor subtype, using COX regression and/or Kaplan-Meier published until June 2018 were identified in PubMed, VHL, Scopus and Web of Science databases. Results: There were selected 23 studies from 446 identified. Women with triple negative tumors in higher BMI categories presented worse survival in four of the seventeen studies including this subtype. In cases of luminal tumors, high BMI was a negative prognostic factor in seven of the eleven studies. For HER2 (Human Epidermal growth factor Receptor-type 2) overexpressed, there was worse survival for higher BMI in two of the six studies. Among HER2 positive women regardless of hormone status, it was observed worse survival for women with higher BMI in two of the five studies. Conclusion: The effect of BMI on the survival of women with breast cancer appears to be differentiated according to the tumor subtype, and its effect is apparently greater in those with luminal tumors.

Key words: Breast Neoplasms/classification; Body Mass Index; Survival Analysis.
\end{abstract}

Resumen

Introducción: La obesidad se considera un factor pronóstico negativo para las mujeres con cáncer de mama y su influencia sobre el curso de la enfermedad puede diferenciarse en los subtipos moleculares. Objetivo: Analizar la influencia del índice de masa corporal (IMC) en la supervivencia de las mujeres con cáncer de mama según subtipo molecular. Método: Realizada revisión integrativa utilizando estrategia PICOS para formulación de la investigación, identificación de palabras clave y definición de los criterios de elegibilidad. Los estudios que analizaron la influencia del IMC en la supervivencia, por subtipo tumoral, utilizando regresión de COX y/o Kaplan-Meier publicados hasta junio de 2018 fueron identificados en PubMed, BVS, Scopus y Web of Science. Resultados: Se seleccionaron 23 estudios. Las mujeres con tumores triple negativo en las mayores categorías de IMC mostraron peor sobrevida en cuatro de los diecisiete estudios incluyendo esse subtipo. Para casos de tumores lumínicos, IMC elevado fue factor pronóstico negativo en siete entre once estudios. Para HER2 (receptor tipo 2 del factor de crecimiento epidérmico humano) superexpresado, hubo peor sobrevida cuando IMC elevado en dos de los seis estudios. Entre los HER2 positivos independientes del status hormonal, se observó peor sobrevida para mujeres con mayores IMC en dos de los cinco estudios. Conclusión: El efecto del IMC en la supervivencia de las mujeres con cáncer de mama parece ser diferenciado de acuerdo con el subtipo tumoral, siendo su efecto, aparentemente, mayor en aquellas con tumores luminales. Palabras clave: Neoplasias de la Mama/clasificación; Índice de Masa Corporal; Análisis de Supervivencia.

${ }^{1}$ Coordenação de Ensino do Instituto Nacional de Câncer José Alencar Gomes da Silva (INCA). Rio de Janeiro (RJ), Brasil. Orcid iD: https://orcid.org/0000-00027301-5452

${ }^{2}$ Escola Nacional de Saúde Pública da Fundação Oswaldo Cruz (Ensp/Fiocruz). Rio de Janeiro (RJ), Brasil. Orcid iD: https://orcid.org/0000-0002-9900-1825 Endereço para correspondência: Rosilene de Lima Pinheiro. Rua Marquês de Pombal, 125 - 30 andar - Centro. Rio de Janeiro (RJ), Brasil. CEP $20230-240$. E-mail: rpinheiro@inca.gov.br 


\section{INTRODUÇÃO}

O curso clínico do câncer de mama é influenciado por uma série de condiçôes relacionadas às características do tumor, como tamanho, grau nuclear, grau histológico, status de receptores hormonais (RH), para estrogênio (RE) e progesterona (RP), status de receptor tipo 2 do fator de crescimento epidérmico humano (HER2), e à situação clínica da doença ao diagnóstico, como o comprometimento dos linfonodos axilares e a presença de metástases a distância que, em conjunto, vão determinar o prognóstico da doença ${ }^{1}$. Recentes avanços no entendimento acerca das características biológicas dos tumores mamários mostram ser o câncer de mama uma doença complexa e heterogênea, incluindo ao menos quatro subtipos moleculares que exibem perfis de expressão gênica distintos, definidos pela combinação de RE, RP e HER2, com comportamento biológico diferenciado, sendo associados a diferentes respostas terapêuticas e prognósticas².

Adicionalmente, outros fatores prognósticos no câncer de mama têm sido descritos na literatura, entre eles, os relacionados às condições imunológica, hormonal e nutricional do paciente, em especial a obesidade. Estudos epidemiológicos recentes mostram que pacientes sobreviventes de câncer de mama com obesidade ao diagnóstico exibem maior chance de recorrência da doença e de morte, apontando a obesidade com um fator prognóstico negativo ${ }^{3,4}$. Uma metanálise, incluindo 43 estudos publicados entre 1988 a 2009, observou que mulheres obesas ao diagnóstico apresentaram 33\% mais chance de morrer por câncer de mama quando comparadas às não obesas ${ }^{5}$. Uma revisão bibliográfica, incluindo 11 estudos prospectivos, retrospectivos e análises secundárias de ensaios clínicos publicados a partir de 2010, apontou a obesidade ao diagnóstico como fator prognóstico negativo no câncer de mama ${ }^{6}$. Em outra revisão, na qual foram incluídos 17 estudos de coorte, publicados entre 1966 e junho de 2010, que investigaram a associação entre o peso corporal e o prognóstico em câncer de mama, os autores concluíram que há evidências convincentes de que a obesidade, medida por intermédio do índice de massa corporal (IMC), está associada com a mortalidade global; que há provável evidência de relação entre obesidade e mortalidade específica por câncer de mama; e que, no que se refere à associaçáo entre o IMC e a recorrência do câncer de mama, os resultados são menos claros $^{7}$. A interferência da obesidade no prognóstico do câncer de mama tem sido investigada em estudos clínicos em pacientes submetidos a diferentes tipos de tratamentos; entretanto, apesar de muitos desses estudos apontarem um aumento no risco de morte relacionado à obesidade, os resultados ainda são conflitantes ${ }^{8-14}$.
Investigaçóes mais recentes mostram que a influência da obesidade sobre o curso da doença pode ser diferenciada, a depender da interação biológica entre o tecido adiposo e os subtipos moleculares do tumor, o que pode explicar as diferenças nos resultados encontrados em distintos estudos. Dessa forma, a busca por esclarecimento sobre a associação entre a obesidade e o prognóstico nos diferentes subtipos do câncer de mama se faz necessária. Assim, o objetivo do presente estudo foi analisar a produção científica sobre a influência do IMC na sobrevida de mulheres com câncer de mama, incluindo sobrevida livre de doença (SLD), sobrevida global (SG) e sobrevida relacionada ao câncer (SRC), de acordo com os subtipos tumorais, utilizando como estratégia uma revisão integrativa da literatura, com a proposta de realizar síntese e análise narrativa do conhecimento científico produzido sobre o tema investigado.

\section{MÉTODO}

Este estudo foi conduzido tendo como base as recomendaçôes metodológicas para revisão integrativa propostas por Botelho et al. ${ }^{15} \mathrm{e}$ Whittemore e Knafl ${ }^{16}$, e as diretrizes para realização de revisóes sistemáticas de estudos observacionais sobre fatores de risco e prognósticos, propostas pelo Ministério da Saúde ${ }^{17}$.

A revisão integrativa foi sistematizada em seis etapas. Na primeira etapa, foi realizada a formulação da questão de pesquisa; na segunda, a localização dos estudos por intermédio de busca bibliográfica nas bases de dados; na terceira etapa, foi realizada a estratégia de elegibilidade dos estudos com aplicaçáo dos critérios de inclusão e exclusão; na quarta, a extração de dados dos estudos incluídos; na quinta, a análise, interpretação e discussão dos resultados; e, por fim, na sexta etapa, foi realizada a criação deste documento que descreve de forma detalhada a síntese do conhecimento científico produzido. Para uma melhor interpretaçấo dos achados, optou-se por descrever os resultados e a discussão de forma conjunta.

\section{QUESTÃO DE PESQUISA}

A questão de pesquisa foi formulada por intermédio da estratégia PICOS (População; Intervenção/Exposição; Controle; Outcome/Desfecho; Study Design/Desenho do estudo $)^{17}$, sendo considerados: como populaçáo de interesse, mulheres com diagnóstico de câncer de mama classificado por subtipo tumoral; como exposição, obesidade determinada por meio de aferição de IMC; como controle, peso baixo ou normal determinados por intermédio de aferição de IMC; como desfecho, recorrência da doença e morte; como desenho do estudo, coorte. Os componentes PICOS foram utilizados para 
identificar as palavras-chave utilizadas na estratégia de busca e para definir os critérios de elegibilidade para a seleção dos estudos.

\section{LOCALIZAÇ̃̃O DOS ESTUDOS}

As bases de dados utilizadas para localização dos estudos foram PubMed, BVS, Scopus e Web of Science, nas quais foram realizadas buscas com data limite de até 30 de junho de 2018, incluindo as seguintes palavras-chave: breast cancer, molecular phenotype (molecular characteristics or molecular subtype or luminal or HER2 or Triple Negative Breast Neoplasm), Body Mass Index (BMI or overweight or obesity), sem aplicação de filtros. As referências obtidas em cada uma das bases de dados foram listadas em uma planilha única, estruturada no Excel, para identificação das citaçóes repetidas entre as bases de dados e formação da lista de estudos para obtenção dos resumos e avaliação da elegibilidade.

\section{ELEGIBILIDADE DOS ESTUDOS}

A estratégia para seleção dos estudos foi realizada em duas fases: triagem e avaliação da elegibilidade. A triagem dos estudos foi realizada pela leitura dos títulos e dos resumos para identificar os que apresentavam as seguintes características: tratar de estudo sobre câncer de mama em populaçáo feminina, investigando sobrevida por intermédio de estudo analítico do tipo coorte, tendo sido publicado nos idiomas inglês, português ou espanhol. A avaliaçáo da elegibilidade se deu pela leitura dos artigos, na íntegra, e aplicaçáo dos critérios de inclusão e exclusão. Para inclusão, os critérios adotados foram: ter realizado análise da influência do IMC na sobrevida, por subtipo tumoral, utilizando como métodos de análise estatística o risco proporcional de COX, para estimar os riscos de recorrência e morte, e/ou Kaplan-Meier com teste de Log-rank. Foram excluídos os estudos que não apresentaram descrição dos subtipos tumorais, dados de razão de chance (odds ratio) para as categorias de IMC com intervalo de confiança e valores do teste de Log-rank, além daqueles cuja populaçáo estudada já tivesse sido incluída em outro estudo selecionado.

\section{EXTRAÇÃO DE DADOS}

De cada estudo incluído, foram extraídos: autor, ano e país de publicação; dados metodológicos; características da população de estudo; e principais resultados. Os dados metodológicos contemplavam a SLD, a SRC, a SG e suas descriçóes, tempo de sobrevida estudado, os subtipos tumorais analisados (considerando os status de RE e RP e de HER2), forma de obtençáo do peso e altura (aferido ou autorreferido), momento da obtenção dos dados antropométricos, peso, altura e/ou IMC, pontos de corte do IMC, o método de análise de sobrevida (risco proporcional de COX e/ou Kaplan-Meier) e as variáveis utilizadas para ajuste nas análises. Foram coletadas as características da populaçáo estudada: total de mulheres incluídas no estudo; média e desvio-padrão (DP) ou mediana e amplitude da idade; e status menopausal. Os resultados extraídos foram: o tempo mediano de seguimento; os valores de razão de risco (hazard ratio) com os respectivos intervalos de confiança para cada categoria de IMC, estimados pelo modelo de risco proporcional de COX; e os dados da curva de Kaplan-Meier, com os valores $p$ do teste de Log-rank.

Cada etapa foi realizada pelas duas pesquisadoras, separadamente, sendo as seleçôes individuais posteriormente comparadas. Os resultados divergentes foram discutidos para obtenção de consenso.

\section{RESULTADOS E DISCUSSÃO}

A partir das buscas, foram obtidas 446 publicações sobre o tema nas bases de dados consultadas. Considerando a estratégia de elegibilidade, 23 estudos foram incluídos nesta revisão, equivalendo a $5 \%$ do total de resumos obtidos e a 32\% dos artigos lidos (Figura 1).

$\mathrm{Na}$ Tabela 1, são descritas as principais características dos estudos incluídos ${ }^{14,18-39}$. Os 23 estudos foram publicados entre setembro de 2011 e fevereiro de 2018, mostrando que há poucos estudos com esse objeto de investigação e que o tema é relativamente recente. Oito estudos foram realizados com a população da América do Norte (Estados Unidos); nove com a população asiática (China 4, Turquia 3, Japão 1 e Coreia do Sul 1), cinco com a europeia (Itália, Espanha, França e Alemanha) e uma da Oceania (Austrália), revelando a inexistência de estudos realizados com a populaçáo da América do Sul. O número de mulheres incluídas em cada um dos estudos variou entre 112 e 41.021. O tempo mediano de seguimento variou entre 29 meses a 11 anos. Onze estudos estimaram o efeito do IMC na sobrevida por intermédio do modelo risco proporcional de COX, sendo apresentado risco de mortalidade (global e/ou relacionada ao câncer) e/ou de recorrência da doença; dois estudos estimaram as curvas de sobrevida de cada categoria de IMC pelo método Kaplan-Meier, realizando comparação entre elas pelo teste de Log-rank; dez utilizaram ambas as análises. As definiçóes dos tipos de sobrevida considerados na metodologia diferiram entre alguns estudos.

Em relação aos dados antropométricos, dos 23 estudos incluídos nesta revisão, apenas seis informaram, de forma clara, o modo de obtençáo dos indicadores peso e altura: em quatro, o peso e a altura foram diretamente 


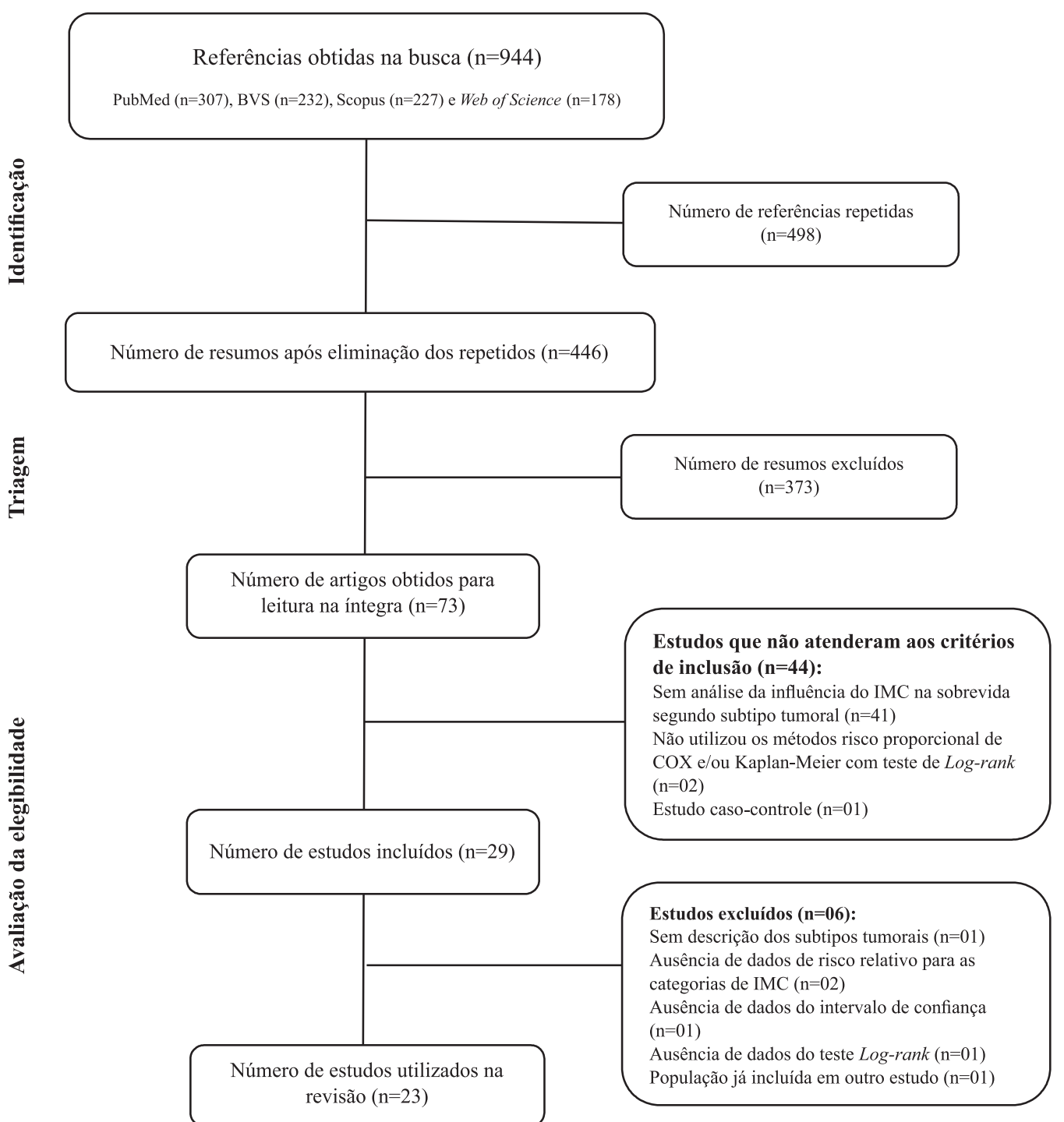

Figura 1. Fluxograma da estratégia de busca e da avaliação de elegibilidade dos estudos

aferidos ${ }^{18-21}$; um deles teve o peso aferido e a altura autorreferida ${ }^{22}$, em um estudo ambos os indicadores foram autorreferidos ${ }^{23}$. Os demais não explicitaram a forma de coleta desses indicadores. No que diz respeito ao momento de obtenção do IMC, em 11 estudos, a obtenção foi ao diagnóstico ${ }^{21,24-33}$, um em uma mediana de tempo de 21 dias após o diagnóstico ${ }^{34}$; em três, no início do estudo ${ }^{19,22,23}$; em três, após a cirurgia, antes do tratamento quimioterápico ${ }^{14,20,35}$; e cinco estudos não apresentaram informaçôes sobre o momento de obtenção do IMC ${ }^{18,36-39}$. Vinte e dois estudos realizaram as análises considerando o IMC como variável categórica, sendo que, em 19 deles, foram adotadas uma ou mais categorias recomendadas pela Organização Mundial da Saúde (OMS) 14-20,22-30,32-34,36,37,39: $<18,5 \mathrm{~kg} / \mathrm{m}^{2}$ (baixo peso), $18,5-24,9 \mathrm{~kg} / \mathrm{m}^{2}$ (peso normal), $25,0-29,9 \mathrm{~kg} / \mathrm{m}^{2}$ (sobrepeso) e $\geq 30 \mathrm{~kg} / \mathrm{m}^{2}$ (obesidade), sendo subcategorizadas em $30,0-34,9 \mathrm{~kg} / \mathrm{m}^{2}$ (obesidade leve), $35-39,9 \mathrm{Kg} / \mathrm{m}^{2}$ (obesidade moderada) e $\geq 40 \mathrm{~kg} / \mathrm{m}^{2}$ (obesidade severa); e, em três estudos, as categorias foram diferenciadas ${ }^{21,31,38}$. Apenas um estudo analisou o IMC como variável contínua, tendo como ponto de corte cinco unidades de aumento de $\operatorname{IMC}^{35}$ (Tabela 1).

O IMC é um importante indicador de saúde, recomendado pela OMS para estimativa da adequação peso/altura e para monitoramento do excesso de peso em âmbito populacional ${ }^{40}$. Sua acurácia é diretamente dependente da precisão na aferição de peso e altura, embora, em estudos populacionais, seja comum o uso da informação autorreferida. Tal estratégia vem sendo adotada com o intuito de viabilizar a realização de estudos epidemiológicos em grandes grupos, especialmente em estudos de campo, proporcionando agilidade no processo de coleta de dados e economia de recursos, uma vez que, para a verificaçáo direta do peso e da altura, são necessários 
Tabela 1. Frequência das variáveis sociodemográficas e clínicas

\begin{tabular}{|c|c|c|c|c|c|}
\hline $\begin{array}{c}\text { Autores/ano/ } \\
\text { país }\end{array}$ & Características gerais & $\begin{array}{l}\text { Definição de } \\
\text { sobrevida }\end{array}$ & Variáveis de ajuste & Subtipo tumoral & $\begin{array}{l}\text { Limitações apontadas } \\
\text { pelos autores }\end{array}$ \\
\hline $\begin{array}{l}\text { Ademuyiwa et al. } \\
(2011)^{24} \\
\text { EUA }\end{array}$ & $\begin{array}{l}\text { Coorte retrospectiva } \\
\text { N. }{ }^{\circ} \text { mulheres incluídas: } 418 \\
\text { Mediana de idade: } 54 \text { anos ( } 26 \text { a } 92 \text { anos) } \\
\text { Status menopausal: } \mathrm{NI} \\
\text { Sobrevida em } 5 \text { anos } \\
\text { Tempo mediano de seguimento: } 37,2 \\
\text { meses } \\
\text { Momento de obtenção do IMC: ao } \\
\text { diagnóstico } \\
\text { Forma de obtenção do peso e da altura: } \\
\mathrm{NI}\end{array}$ & $\begin{array}{l}\text { SLD: tempo entre } \\
\text { o diagnóstico e a } \\
\text { primeira recorrência ou } \\
\text { último seguimento } \\
\text { SG: tempo entre o } \\
\text { diagnóstico e a morte } \\
\text { ou último seguimento }\end{array}$ & $\begin{array}{l}\text { Idade, raça, ano } \\
\text { do diagnóstico, } \\
\text { tipo histológico, } \\
\text { estadiamento, grau } \\
\text { tumoral, presença } \\
\text { de invasão vascular } \\
\text { e quimioterapia }\end{array}$ & TN (RE-/RP-/HER2-) & $\begin{array}{l}\text { Reduzido n. }{ }^{0} \text { de eventos, } \\
\text { parcialmente em razão } \\
\text { do curto tempo mediano } \\
\text { de seguimento e da } \\
\text { preponderância de estágio } \\
\text { precoce da doença; ausência } \\
\text { de informações sobre } \\
\text { consumo de álcool e prática } \\
\text { de atividade física }\end{array}$ \\
\hline $\begin{array}{l}\text { Dawood et al. } \\
(2012)^{36} \\
\text { EUA }\end{array}$ & $\begin{array}{l}\text { Coorte retrospectiva } \\
\text { N. }{ }^{\circ} \text { mulheres incluídas: } 2.311 \\
\text { Mediana de idade: NI } \\
\text { Status menopausal: pré e pós-menopausa } \\
\text { Sobrevida em } 5 \text { anos } \\
\text { Tempo mediano de seguimento: } 39 \text { meses } \\
\text { Momento de obtenção do IMC: NI } \\
\text { Forma de obtenção do peso e da altura: } \\
\mathrm{NI}\end{array}$ & $\begin{array}{l}\text { SLD: tempo entre a } \\
\text { data do diagnóstico e a } \\
\text { primeira recorrência ou } \\
\text { último seguimento } \\
\text { SG: tempo entre } 0 \\
\text { diagnóstico e a morte } \\
\text { ou último seguimento }\end{array}$ & $\begin{array}{l}\text { Idade, raça, } \\
\text { estadiamento, } \\
\text { invasão linfática } \\
\text { e vascular, } \\
\text { tratamentos: } \\
\text { adjuvante sistêmico } \\
\text { e radioterapia }\end{array}$ & TN (RE-/RP-/HER2-) & $\begin{array}{l}\text { Natureza retrospectiva; } \\
\text { curto tempo mediano de } \\
\text { seguimento; ausência de } \\
\text { informações sobre alterações } \\
\text { no IMC após o diagnóstico; } \\
\text { ausência de informações sobre } \\
\text { outros fatores modificáveis } \\
\text { relacionados ao estilo de vida, } \\
\text { como atividade física }\end{array}$ \\
\hline $\begin{array}{l}\text { Sparano et al. } \\
(2012)^{14} \\
\text { EUA }\end{array}$ & $\begin{array}{l}\text { Coorte a partir de um ensaio clínico } \\
\text { (temporalidade não informada) } \\
\text { N.o mulheres incluídas: } 4.770 \\
\text { Mediana de idade: NI } \\
\text { Status menopausal: pré e pós-menopausa } \\
\text { Sobrevida em } 8 \text { anos } \\
\text { Tempo mediano de seguimento: } 7,9 \text { anos } \\
\text { Momento de obtenção do IMC: após a } \\
\text { cirurgia, antes da quimioterapia } \\
\text { Forma de obtenção do peso e da altura: } \\
\mathrm{NI}\end{array}$ & $\begin{array}{l}\text { SLD: tempo entre } \\
\text { a randomização e } \\
\text { o primeiro evento, } \\
\text { incluindo recorrência } \\
\text { da doença, câncer de } \\
\text { mama contralateral } \\
\text { ou morte por qualquer } \\
\text { causa } \\
\text { SG: tempo entre a data } \\
\text { da randomização até } \\
\text { a morte por qualquer } \\
\text { causa } \\
\text { SRC: morte atribuída } \\
\text { ao câncer de mama } \\
\text { ou precedida pela } \\
\text { recorrência da doença, } \\
\text { com seguimento } \\
\text { censurado na data } \\
\text { da morte por outras } \\
\text { causas }\end{array}$ & $\begin{array}{l}\text { Idade, raça, status } \\
\text { menopausal, } \\
\text { tamanho tumoral, } \\
\mathrm{n}^{0}{ }^{\circ} \text { de nódulo } \\
\text { linfático axilar } \\
\text { positivo, tipo } \\
\text { de cirurgia, } \\
\text { radioterapia, } \\
\text { quimioterapia e } \\
\text { hormonioterapia } \\
\text { (dependendo do } \\
\text { braço de tratamento } \\
\text { do ensaio clínico) }\end{array}$ & $\begin{array}{l}\text { Luminal (RE e/ou } \\
\text { RP+/HER2- ou } \\
\text { desconhecido) } \\
\text { HER2 superexpresso } \\
\text { (RE-/RP-/HER2+) } \\
\text { TN (RE-/RP-/HER2-) }\end{array}$ & $\mathrm{NI}$ \\
\hline $\begin{array}{l}\text { Crozier et al. } \\
(2013)^{22} \\
\text { EUA }\end{array}$ & $\begin{array}{l}\text { Coorte a partir de um ensaio clínico } \\
\text { (temporalidade não informada) } \\
\text { N. }{ }^{0} \text { mulheres incluídas: } 3.017 \\
\text { Mediana de idade: NI } \\
\text { Status menopausal: pré e pós-menopausa } \\
\text { Sobrevida em } 5 \text { anos } \\
\text { Tempo mediano de seguimento: } 5,3 \text { anos } \\
\text { Momento de obtenção do IMC: início do } \\
\text { estudo } \\
\text { Forma de obtenção do peso e da altura: } \\
\text { peso aferido e altura reportada }\end{array}$ & $\begin{array}{l}\text { SLD: tempo entre } \\
\text { o diagnóstico e o } \\
\text { primeiro evento } \\
\text { relacionado à doença } \\
\text { (recorrência da doença } \\
\text { local, regional ou a } \\
\text { distância, câncer de } \\
\text { mama contralateral, } \\
\text { um novo câncer } \\
\text { primário (exceto } \\
\text { carcinoma de pele } \\
\text { de célula basal ou } \\
\text { escamosa, carcinoma } \\
\text { in situ de cérvix ou } \\
\text { carcinoma lobular } \\
\text { in situ de mama) ou } \\
\text { morte por qualquer } \\
\text { causa) }\end{array}$ & Idade e raça & HER2 + (RH + /-) & $\begin{array}{l}\text { Baixo poder para detectar } \\
\text { pequenas diferenças } \\
\text { estatísticas entre os braços de } \\
\text { tratamentos e sua interaçáo } \\
\text { com as três categorias de IMC }\end{array}$ \\
\hline
\end{tabular}


Tabela 1. continuação

\begin{tabular}{|c|c|c|c|c|c|}
\hline $\begin{array}{c}\text { Autores/ano/ } \\
\text { país }\end{array}$ & Características gerais & $\begin{array}{l}\text { Definição de } \\
\text { sobrevida }\end{array}$ & Variáveis de ajuste & Subtipo tumoral & $\begin{array}{l}\text { Limitações apontadas } \\
\text { pelos autores }\end{array}$ \\
\hline $\begin{array}{l}\text { Mazzarella et al. } \\
(2013)^{18} \\
\text { Itália }\end{array}$ & $\begin{array}{l}\text { Coorte retrospectiva } \\
\text { N. }{ }^{0} \text { mulheres incluídas: } 1.250 \\
\text { Mediana de idade: } \mathrm{NI} \\
\text { Status menopausal: pré e pós-menopausa } \\
\text { Sobrevida em } 5 \text { anos } \\
\text { Tempo mediano de seguimento: } 8,2 \text { anos } \\
\text { Momento de obtenção do IMC: } \mathrm{NI} \\
\text { Forma de obtenção do peso e da altura: } \\
\text { aferidos }\end{array}$ & $\begin{array}{l}\text { SLD: tempo entre } \\
\text { a cirurgia e o } \\
\text { aparecimento do } \\
\text { primeiro evento } \\
\text { (recorrência, segundo } \\
\text { câncer primário } \\
\text { incluindo câncer de } \\
\text { mama contralateral ou } \\
\text { morte) } \\
\text { SG: tempo entre a } \\
\text { cirurgia e a data da } \\
\text { morte por qualquer } \\
\text { causa }\end{array}$ & $\begin{array}{l}\text { Idade ao } \\
\text { diagnóstico, status } \\
\text { menopausal, } \\
\text { número de } \\
\text { linfonodos positivos, } \\
\text { tamanho do tumor, } \\
\text { grau tumoral, } \\
\text { percentual de células } \\
\text { receptor estrogênio } \\
\text { positivas, invasão } \\
\text { perivascular e tipo } \\
\text { de cirurgia }\end{array}$ & $\begin{array}{l}\text { Luminal (RE + I } \\
\text { HER2 +) } \\
\text { HER2 superexpresso } \\
\text { (RE-/HER2 + ) }\end{array}$ & $\begin{array}{l}\text { Natureza retrospectiva; } \\
\text { pequeno número de } \\
\text { pacientes obesos; ausência } \\
\text { de informações sobre dose do } \\
\text { tratamento }\end{array}$ \\
\hline $\begin{array}{l}\text { Mowad et al. } \\
(2013)^{25} \\
\text { EUA }\end{array}$ & $\begin{array}{l}\text { Coorte retrospectiva } \\
\text { N. }{ }^{\circ} \text { mulheres incluídas: } 183 \\
\text { Média de idade: } 49,8 \text { anos } \\
\text { Status menopausal: } \mathrm{NI} \\
\text { Sobrevida em } 5 \text { anos } \\
\text { Tempo mediano de seguimento: } 42,5 \\
\text { meses. } \\
\text { Momento de obtenção do IMC: ao } \\
\text { diagnóstico } \\
\text { Forma de obtenção do peso e da altura: } \\
\mathrm{NI}\end{array}$ & $\begin{array}{l}\text { SLD: tempo entre a } \\
\text { data do diagnóstico } \\
\text { e a data da primeira } \\
\text { recorrência (local ou a } \\
\text { distância) ou a data do } \\
\text { último seguimento } \\
\text { SG: tempo entre a data } \\
\text { do diagnóstico e a data } \\
\text { de morte por qualquer } \\
\text { causa ou a última data } \\
\text { de seguimento }\end{array}$ & $\mathrm{NI}$ & TN (RE-/RP-/HER2-) & $\mathrm{NI}$ \\
\hline $\begin{array}{l}\text { Pajares et al. } \\
(2013)^{19} \\
\text { Espanha }\end{array}$ & $\begin{array}{l}\text { Coorte retrospectiva a partir de um ensaio } \\
\text { clínico } \\
\text { N. }{ }^{\circ} \text { mulheres incluídas: } 5.683 \\
\text { Mediana de idade: NI } \\
\text { Status menopausal: pré e pós-menopausa } \\
\text { Sobrevida em } 10 \text { anos } \\
\text { Tempo mediano de seguimento: } 93,4 \\
\text { meses } \\
\text { Momento de obtenção do IMC: início do } \\
\text { estudo } \\
\text { Forma de obtenção do peso e da altura: } \\
\text { aferidos }\end{array}$ & $\begin{array}{l}\text { SLD: tempo até a } \\
\text { recorrência (local, } \\
\text { regional ou a distância) } \\
\text { ou segundo câncer de } \\
\text { mama primário (exceto } \\
\text { in situ) } \\
\text { SG: tempo até a morte } \\
\text { por qualquer causa } \\
\text { SRC: tempo até a } \\
\text { morte por câncer de } \\
\text { mama }\end{array}$ & $\begin{array}{l}\text { Idade, status } \\
\text { menopausal, } \\
\text { tamanho tumoral, } \\
\text { status nodal, grau } \\
\text { histológico, status de } \\
\text { RH, status de HER2, } \\
\text { tipo de cirurgia, } \\
\text { subtratamento } \\
\text { global, estudo } \\
\text { (incluindo status } \\
\text { nodal) }\end{array}$ & $\begin{array}{l}\text { Luminal (RE e/ou } \\
\text { RP+/HER2-) } \\
\text { HER2+ (RH +/-) } \\
\text { TN (RE-/RP-/HER2-) } \\
\text { Desconhecido }\end{array}$ & $\begin{array}{l}\text { Natureza retrospectiva; IMC } \\
\text { mensurado apenas no início } \\
\text { de seguimento (alterações } \\
\text { no IMC não mensurados); } \\
\text { ausência de informação sobre } \\
\text { HER2 no trial GEICAM/9805, } \\
\text { reduzindo o poder da análise } \\
\text { estatística }\end{array}$ \\
\hline $\begin{array}{l}\text { Turkoz et al. } \\
(2013)^{26} \\
\text { Turquia }\end{array}$ & $\begin{array}{l}\text { Coorte retrospectiva } \\
\text { N. }{ }^{\circ} \text { mulheres incluídas: } 733 \\
\text { Mediana de idade: NI } \\
\text { Status menopausal: pré-menopausa } \\
\text { Sobrevida em } 5 \text { anos } \\
\text { Tempo mediano de seguimento: } 29 \text { meses } \\
\text { Momento de obtenção do IMC: a } \\
\text { diagnóstico } \\
\text { Forma de obtenção do peso e da altura: } \\
\mathrm{NI}\end{array}$ & $\begin{array}{l}\text { SLD: tempo entre a } \\
\text { data do diagnóstico e } \\
\text { a data da recorrência } \\
\text { (local ou a distância) } \\
\text { SG: tempo entre a data } \\
\text { do diagnóstico e a data } \\
\text { de morte por câncer de } \\
\text { mama (Considerado } \\
\text { SRC nesta revisão) }\end{array}$ & $\begin{array}{l}\text { Idade, tamanho } \\
\text { tumoral, } \\
\text { envolvimento } \\
\text { nodal, grau } \\
\text { histológico, invasão } \\
\text { linfovascular e } \\
\text { perineural, extensão } \\
\text { extracapsular, status } \\
\text { hormonal }\end{array}$ & $\begin{array}{l}\text { Luminal (RE e/ou } \\
\text { RP+/HER2-) } \\
\text { HER2 superexpresso } \\
\text { (RH-/HER2+) } \\
\text { TN (RE/RP-/HER2-) }\end{array}$ & $\begin{array}{l}\text { Número reduzido de casos } \\
\text { TN e de HER2 superexpresso; } \\
\text { ausência de mensuração } \\
\text { da adiposidade central/ } \\
\text { abdominal e de informações } \\
\text { sobre alteração do } \\
\text { tratamento ao longo dos } 10 \\
\text { anos de seguimento }\end{array}$ \\
\hline $\begin{array}{l}\text { Robinson et al. } \\
(2014)^{23} \\
\text { Austrália }\end{array}$ & $\begin{array}{l}\text { Coorte prospectiva } \\
\text { N. }{ }^{\circ} \text { mulheres incluídas: } 1.155 \\
\text { Média de idade: } 58,4 \text { anos } \\
\text { Status menopausal: NI } \\
\text { Sobrevida em } 5 \text { anos } \\
\text { Tempo mediano de seguimento: } 5,6 \text { anos } \\
\text { Momento de obtenção do IMC: início } \\
\text { do estudo, em média } 0,8 \text { meses após o } \\
\text { diagnóstico } \\
\text { Forma de obtenção do peso e da altura: } \\
\text { autorreportados }\end{array}$ & $\begin{array}{l}\text { Para análise de } \\
\text { sobrevida, a data da } \\
\text { recorrência (recidiva } \\
\text { da doença na mesma } \\
\text { mama, doença } \\
\text { metastática ou câncer } \\
\text { envolvendo a outra } \\
\text { mama) ou morte } \\
\text { pelo câncer de mama } \\
\text { constituíram um evento } \\
\text { (Considerado SLD } \\
\text { nesta revisão) }\end{array}$ & $\mathrm{NI}$ & $\begin{array}{l}\text { Luminal (RE e/ou } \\
\text { RP +/HER2-) }\end{array}$ & $\begin{array}{l}\text { Momento e forma de aferição } \\
\text { do IMC }\end{array}$ \\
\hline
\end{tabular}


Tabela 1. continuação

\begin{tabular}{|c|c|c|c|c|c|}
\hline $\begin{array}{c}\text { Autores/ano/ } \\
\text { país }\end{array}$ & Características gerais & $\begin{array}{l}\text { Definição de } \\
\text { sobrevida }\end{array}$ & Variáveis de ajuste & Subtipo tumoral & $\begin{array}{l}\text { Limitações apontadas } \\
\text { pelos autores }\end{array}$ \\
\hline $\begin{array}{l}\text { Tait et al. } \\
(2014)^{27} \\
\text { EUA }\end{array}$ & $\begin{array}{l}\text { Coorte retrospectiva } \\
\text { N.․ mulheres incluídas: } 448 \\
\text { Mediana de idade: NI } \\
\text { Status menopausal: pré e pós-menopausa } \\
\text { Sobrevida em } 5 \text { anos } \\
\text { Tempo mediano de seguimento: } 40,1 \\
\text { meses } \\
\text { Momento de obtenção do IMC: ao } \\
\text { diagnóstico } \\
\text { Forma de obtenção do peso e da altura: NI }\end{array}$ & $\begin{array}{l}\text { SLD: tempo entre a } \\
\text { cirurgia e a recorrência } \\
\text { (local ou a distância) } \\
\text { ou morte } \\
\text { SG: tempo entre o } \\
\text { diagnóstico e a morte } \\
\text { por qualquer causa } \\
\text { ou data do último } \\
\text { seguimento }\end{array}$ & $\begin{array}{l}\text { Estadiamento } \\
\text { patológico }\end{array}$ & TN (RE-/RP-/HER2-) & $\begin{array}{l}\text { Natureza retrospectiva; } \\
\text { período de seguimento } \\
\text { relativamente curto, ausência } \\
\text { de informações sobre } \\
\text { alteração do IMC após o } \\
\text { diagnóstico, homogeneidade } \\
\text { dos pacientes no que se refere } \\
\text { ao acesso à diagnóstico, } \\
\text { tratamento e seguimento, } \\
\text { podendo ter gerado viés de } \\
\text { seleção }\end{array}$ \\
\hline $\begin{array}{l}\text { Xiao et al. } \\
(2014)^{28} \\
\text { China }\end{array}$ & $\begin{array}{l}\text { Coorte retrospectiva } \\
\text { N.․ mulheres incluídas: } 5.785 \\
\text { Mediana de idade: NI } \\
\text { Status menopausal: pré e pós-menopausa } \\
\text { Sobrevida em } 5 \text { anos } \\
\text { Tempo mediano de seguimento: } 70 \text { meses } \\
\text { Momento de obtenção do IMC: ao } \\
\text { diagnóstico } \\
\text { Forma de obtenção do peso e da altura: NI }\end{array}$ & $\begin{array}{l}\text { SRC: tempo entre } \\
\text { o diagnóstico e a } \\
\text { morte relacionada à } \\
\text { doença ou o último } \\
\text { seguimento }\end{array}$ & $\mathrm{NI}$ & $\begin{array}{l}\text { Luminal A } \\
\text { Luminal B (HER2-/ } \\
\text { neu+) } \\
\text { Luminal B (Ki67 } \\
\text { elevado) }\end{array}$ & $\begin{array}{l}\text { Natureza retrospectiva; } \\
\text { diferenças no tempo de } \\
\text { medicação e } \mathrm{n}^{0} \text { de drogas } \\
\text { entre os pacientes; controle } \\
\text { glicêmico e extensão da } \\
\text { doença não foi claro entre os } \\
\text { pacientes }\end{array}$ \\
\hline $\begin{array}{l}\text { Bonsang-Kitzis et } \\
\text { al. }(2015)^{37} \\
\text { França }\end{array}$ & $\begin{array}{l}\text { Coorte retrospectiva } \\
\text { N. }{ }^{0} \text { mulheres incluídas: } 326 \\
\text { Mediana de idade: } 47 \text { anos ( } 25 \text { a } 76 \text { ) } \\
\text { Status menopausal: pré e pós-menopausa } \\
\text { Sobrevida em } 3 \text { anos } \\
\text { Tempo mediano de seguimento: } 52 \text { meses } \\
\text { Momento de obtenção do IMC: NI } \\
\text { Forma de obtenção do peso e da altura: NI }\end{array}$ & $\begin{array}{l}\text { SLD: tempo entre } \\
\text { o tratamento } \\
\text { quimioterápico } \\
\text { neoadjuvante e a } \\
\text { recorrência da doença } \\
\text { ou último seguimento }\end{array}$ & $\mathrm{NI}$ & TN (RE-/RP-/HER2-) & $\mathrm{NI}$ \\
\hline $\begin{array}{l}\text { Cakar et al. } \\
(2015)^{29} \\
\text { Turquia }\end{array}$ & $\begin{array}{l}\text { Coorte retrospectiva } \\
\mathrm{N} .{ }^{0} \text { mulheres incluídas: } 112 \\
\text { Média de idade: } 50,4 \\
\text { Status menopausal: pré e pós-menopausa } \\
\text { Sobrevida: NI } \\
\text { Tempo mediano de seguimento: } 29,4 \\
\text { meses } \\
\text { Momento de obtenção do IMC: ao } \\
\text { diagnóstico } \\
\text { Forma de obtenção do peso e da altura: NI }\end{array}$ & $\begin{array}{l}\text { SLD: tempo entre } \\
\text { o diagnóstico e a } \\
\text { primeira recorrência da } \\
\text { doença ou metástase } \\
\text { SG: tempo entre } \\
\text { diagnóstico e a morte } \\
\text { ou último seguimento }\end{array}$ & Status menopausal & TN (RE-/RP-/HER2-) & Pequeno número de pacientes \\
\hline $\begin{array}{l}\text { Fan et al. } \\
(2015)^{30} \\
\text { China }\end{array}$ & $\begin{array}{l}\text { Coorte retrospectiva } \\
\text { N. }{ }^{0} \text { mulheres incluídas: } 1.249 \\
\text { Mediana de idade: } 49 \text { anos } \\
\text { Status menopausal: } \mathrm{NI} \\
\text { Sobrevida em } 5 \text { anos } \\
\text { Tempo mediano de seguimento: } 79 \text { meses } \\
\text { Momento de obtenção do IMC: ao } \\
\text { diagnóstico } \\
\text { Forma de obtenção do peso e da altura: NI }\end{array}$ & $\begin{array}{l}\text { SLD: tempo entre a } \\
\text { data do diagnóstico } \\
\text { e a data da primeira } \\
\text { recorrência (local ou a } \\
\text { distância) ou do último } \\
\text { seguimento } \\
\text { SG: tempo entre a data } \\
\text { do diagnóstico e a data } \\
\text { de morte ou do último } \\
\text { seguimento }\end{array}$ & $\mathrm{NI}$ & $\begin{array}{l}\text { TN (RE-/RP-/HER2-) } \\
\text { Não TN }\end{array}$ & $\begin{array}{l}\text { Natureza retrospectiva; } \\
\text { definição de obesidade } \\
\text { apenas por IMC; estilo de } \\
\text { vida, drogas endócrinas e } \\
\text { quimioterapia podem afetar } \\
\text { o perfil lipídico, podendo agir } \\
\text { como fatores confundidores } \\
\text { na análise de associação } \\
\text { entre HDL e sobrevida }\end{array}$ \\
\hline $\begin{array}{l}\text { Hao et al. }(2015)^{31} \\
\text { China }\end{array}$ & $\begin{array}{l}\text { Coorte retrospectiva } \\
\mathrm{N} .{ }^{\circ} \text { mulheres incluídas: } 1.106 \\
\text { Mediana de idade: NI } \\
\text { Status menopausal: pré e pós-menopausa } \\
\text { Sobrevida: NI } \\
\text { Tempo mediano de seguimento: } 44,8 \\
\text { meses } \\
\text { Momento de obtenção do IMC: ao } \\
\text { diagnóstico } \\
\text { Forma de obtenção do peso e da altura: NI }\end{array}$ & $\begin{array}{l}\text { SRC: tempo entre a } \\
\text { cirurgia e a data da } \\
\text { morte relacionada ao } \\
\text { câncer de mama } \\
\text { SG: tempo entre a data } \\
\text { da cirurgia e a data } \\
\text { da morte por qualquer } \\
\text { causa ou data do } \\
\text { último seguimento }\end{array}$ & $\begin{array}{l}\text { Idade, status } \\
\text { menopausal, } \\
\text { tamanho tumoral, } \\
\text { status nodal, grau } \\
\text { e terapia adjuvante } \\
\text { sistêmica }\end{array}$ & TN (RE-/RP-/HER2-) & $\begin{array}{l}\text { Proporção entre baixo peso } \\
\text { e obesidade; classificação do } \\
\text { IMC em escala binária, sem } \\
\text { distinção entre sobrepeso } \\
\text { e obesidade; totalidade de } \\
\text { pacientes em estadiamento } \\
\text { precoce com tratamento } \\
\text { cirúrgico, não sendo possível } \\
\text { análise de subgrupo de } \\
\text { pacientes com tratamento } \\
\text { neoadjuvante; estudo com } \\
\text { apenas um grupo étnico, não } \\
\text { sendo possível extrapolar os } \\
\text { resultados }\end{array}$ \\
\hline
\end{tabular}


Tabela 1. continuação

\begin{tabular}{|c|c|c|c|c|c|}
\hline $\begin{array}{c}\text { Autores/ano/ } \\
\text { país }\end{array}$ & Características gerais & $\begin{array}{l}\text { Definição de } \\
\text { sobrevida }\end{array}$ & Variáveis de ajuste & Subtipo tumoral & $\begin{array}{l}\text { Limitações apontadas } \\
\text { pelos autores }\end{array}$ \\
\hline $\begin{array}{l}\text { Jeon et al. } \\
(2015)^{32} \\
\text { Coreia }\end{array}$ & $\begin{array}{l}\text { Coorte retrospectiva } \\
\text { N. }{ }^{\circ} \text { mulheres incluídas: } 41.021 \\
\text { Média de idade: } 48 \text { anos (18 a 93) } \\
\text { Status menopausal: NI } \\
\text { Sobrevida: NI } \\
\text { Tempo mediano de seguimento: } 92 \text { meses } \\
\text { Momento de obtenção do IMC: ao } \\
\text { diagnóstico } \\
\text { Forma de obtenção do peso e da altura: } \\
\mathrm{NI}\end{array}$ & $\begin{array}{l}\text { SG: tempo entre a data } \\
\text { do diagnóstico e a data } \\
\text { de morte por qualquer } \\
\text { causa } \\
\text { SRC: tempo entre a } \\
\text { data do diagnóstico e } \\
\text { a data da morte por } \\
\text { câncer de mama }\end{array}$ & $\begin{array}{l}\text { Idade, tamanho } \\
\text { tumoral, status } \\
\text { nodal, grau } \\
\text { histológico, método } \\
\text { cirúrgico, tratamento } \\
\text { adjuvante, status de } \\
\text { RE e RP e expressão } \\
\text { de HER2 }\end{array}$ & $\begin{array}{l}\text { Luminal (RE e/ou } \\
\text { RP +/HER2-) } \\
\text { Luminal (RE e/ou } \\
\text { RP+/HER2+) } \\
\text { HER2 superexpresso } \\
\text { (RE-/RP-/HER2+) } \\
\text { TN (RE-/RP-/HER2-) } \\
\text { Desconhecido }\end{array}$ & $\begin{array}{l}\text { Limitação da base de } \\
\text { dados (heterogeneidade no } \\
\text { estadiamento da doença, } \\
\text { na imuno-histoquímica e na } \\
\text { presença de comorbidade); } \\
\text { registro de dados essenciais } \\
\text { (IMC e RH) avaliável em } \\
\text { somente } 62,84 \% \text { dos } \\
\text { pacientes, podendo causar } \\
\text { viés de seleção; pequeno } \\
\text { tamanho amostral para } \\
\text { baixo peso e obesidade; } \\
\text { homogeneidade étnica, } \\
\text { limitando a generalização } \\
\text { para outros grupos raciais }\end{array}$ \\
\hline $\begin{array}{l}\text { Ligibel et al. } \\
(2015)^{35} \\
\text { EUA }\end{array}$ & $\begin{array}{l}\text { Coorte retrospectiva a partir de um ensaio } \\
\text { clínico } \\
\text { N. }{ }^{\circ} \text { mulheres incluídas: } 1.272 \\
\text { Mediana de idade: } 50 \text { anos } \\
\text { Status menopausal: pré e pós-menopausa } \\
\text { Sobrevida: NI } \\
\text { Tempo mediano de seguimento: } 11 \text { anos } \\
\text { Momento de obtenção do IMC: após a } \\
\text { cirurgia, antes da quimioterapia } \\
\text { Forma de obtenção do peso e da altura: NI }\end{array}$ & $\begin{array}{l}\text { SLD: tempo entre a } \\
\text { inclusão no estudo e a } \\
\text { primeira recorrência } \\
\text { (local ou a distância) } \\
\text { ou morte sem } \\
\text { recorrência ou data do } \\
\text { último seguimento }\end{array}$ & Não ajustado & $\begin{array}{l}\text { Luminal A } \\
\text { Luminal B } \\
\text { HER2 superexpresso } \\
\text { (RE-/RP-/HER2+) } \\
\text { TN (RE-/RP-/HER2-) }\end{array}$ & $\begin{array}{l}\text { Natureza retrospectiva; } \\
\text { tamanho amostral; PAM50 } \\
\text { avaliado apenas para um } \\
\text { subgrupo de pacientes; } \\
\text { ausência de informações } \\
\text { sobre adesão à terapia } \\
\text { endócrina; população em sua } \\
\text { maioria branca }\end{array}$ \\
\hline $\begin{array}{l}\text { Widschwendter et } \\
\text { al. }(2015)^{20} \\
\text { Alemanha }\end{array}$ & $\begin{array}{l}\text { Coorte retrospectiva a partir de um ensaio } \\
\text { clínico } \\
\text { NN. }{ }^{\circ} \text { mulheres incluídas: } 3.670 \\
\text { Mediana de idade: } 53 \text { anos ( } 21 \text { a } 86 \text { ) } \\
\text { Status menopausal: pré e pós-menopausa } \\
\text { Sobrevida: NI } \\
\text { Tempo mediano de seguimento: } 65 \text { meses } \\
\text { Momento de obtenção do IMC: antes do } \\
\text { início da quimioterapia } \\
\text { Forma de obtenção do peso e da altura: } \\
\text { aferidos }\end{array}$ & $\begin{array}{l}\text { SLD: período entre } \\
\text { o diagnóstico e a } \\
\text { recorrência (local, } \\
\text { contralateral e a } \\
\text { distância, tumor } \\
\text { primário/secundário) } \\
\text { ou morte por qualquer } \\
\text { causa ou data do } \\
\text { último seguimento } \\
\text { SG: morte por } \\
\text { qualquer causa ou data } \\
\text { do último seguimento }\end{array}$ & $\begin{array}{l}\text { Idade, tamanho } \\
\text { tumoral, status } \\
\text { nodal, grau tumoral, } \\
\text { tipo histológico, } \\
\text { status de receptor } \\
\text { hormonal, status } \\
\text { de HER2, status } \\
\text { menopausal, tipo de } \\
\text { cirurgia, tratamento } \\
\text { quimioterápico, } \\
\text { terapia hormonal } \\
\text { e subtratamento } \\
\text { quimioterápico }\end{array}$ & $\begin{array}{l}\text { Luminal A like } \\
\text { (RH+/HER2-/G1/ } \\
\text { G2) } \\
\text { Luminal B like } \\
\text { (RH+/HER2-/G3) } \\
\text { HER2 + (RH + /-) } \\
\text { TN (RE-/RP-/HER2-) }\end{array}$ & $\begin{array}{l}\text { Ausência de informações } \\
\text { sobre Ki67; baixo n. } \\
\text { pacientes com obesidade } \\
\text { severa, ausência de dados } \\
\text { sobre síndrome metabólica }\end{array}$ \\
\hline $\begin{array}{l}\text { Bao et al. } \\
(2016)^{21} \\
\text { China }\end{array}$ & $\begin{array}{l}\text { Coorte prospectiva } \\
\text { N. }{ }^{\circ} \text { mulheres incluídas: } 518 \\
\text { Média de idade: } 53,4 \text { anos (DP } \pm 10,6) \\
\text { Status menopausal: pré e pós-menopausa } \\
\text { Sobrevida em } 10 \text { anos } \\
\text { Tempo mediano de seguimento: } 9,1 \text { anos } \\
\text { Momento de obtenção do IMC: ao } \\
\text { diagnóstico } \\
\text { Forma de obtenção do peso e da altura: } \\
\text { aferidos }\end{array}$ & $\begin{array}{l}\text { SLD: tempo entre } \\
\text { o diagnóstico e a } \\
\text { recorrência da doença } \\
\text { ou metástase e morte } \\
\text { por câncer de mama } \\
\text { SG: tempo entre o } \\
\text { diagnóstico e a morte } \\
\text { por qualquer causa }\end{array}$ & $\begin{array}{l}\text { Idade, nível } \\
\text { educacional, status } \\
\text { menopausal, index } \\
\text { de comorbidade } \\
\text { Charlson, } \\
\text { participação } \\
\text { em exerćcio, } \\
\text { estadiamento TNM, } \\
\text { tipo de cirurgia, } \\
\text { quimioterapia e } \\
\text { radioterapia }\end{array}$ & TN (RE-/RP-/HER2-) & $\begin{array}{l}\text { Análise estatística insuficiente } \\
\text { para explorar interação entre } \\
\text { IMC e outros fatores, o que } \\
\text { pode explicar a ausência de } \\
\text { significância }\end{array}$ \\
\hline $\begin{array}{l}\text { Kawai et al. } \\
(2016)^{38} \\
\text { Japão }\end{array}$ & $\begin{array}{l}\text { Coorte retrospectiva } \\
\text { N. }{ }^{0} \text { mulheres incluídas: } 20.090 \\
\text { Média de idade: } 57,3 \text { anos (DP } \pm 12,8) \\
\text { Status menopausal: pré e pós-menopausa } \\
\text { Sobrevida em } 8 \text { anos } \\
\text { Tempo mediano de seguimento: } 6,7 \text { anos } \\
\text { Momento de obtenção do IMC: } \mathrm{NI} \\
\text { Forma de obtenção do peso e da altura: } \\
\mathrm{NI}\end{array}$ & $\begin{array}{l}\text { SLD: tempo entre } \\
\text { a data do primeiro } \\
\text { tratamento e a data da } \\
\text { recorrência (local ou a } \\
\text { distância) ou do final } \\
\text { do seguimento } \\
\text { SRC: tempo entre } \\
\text { a data do primeiro } \\
\text { tratamento e a data } \\
\text { da morte por câncer de } \\
\text { mama ou do final do } \\
\text { seguimento }\end{array}$ & $\begin{array}{l}\text { Idade, região de } \\
\text { residência, método } \\
\text { de detecção, } \\
\text { história familiar do } \\
\text { câncer de mama, } \\
\text { estágio tumoral, } \\
\text { radioterapia, } \\
\text { quimioterapia, } \\
\text { terapia endócrina, } \\
\text { status menopausal e } \\
\text { ano de registro }\end{array}$ & $\begin{array}{l}\text { Luminal A (RE+/ } \\
\text { RP+/HER2-) } \\
\text { Luminal B (RE+/ } \\
\text { RP-/HER2- ou RE + / } \\
\text { HER2+) } \\
\text { HER2 superexpresso } \\
\text { (RE-/RP-/HER2+) } \\
\text { TN (RE-/RP-/HER2-) } \\
\text { Outros }^{\text {b }}\end{array}$ & $\begin{array}{l}\text { Momento da aferição do } \\
\text { peso; taxa de seguimento } \\
\text { relativamente baixo; } \\
\text { ausência de informações } \\
\text { sobre comorbidades, } \\
\text { composição corporal e } \\
\text { variáveis confundidoras } \\
\text { (fumo, álcool e atividade } \\
\text { física); homogeneidade } \\
\text { étnica, comprometendo a } \\
\text { validade externa }\end{array}$ \\
\hline
\end{tabular}


Tabela 1. continuação

\begin{tabular}{|c|c|c|c|c|c|}
\hline $\begin{array}{c}\text { Autores/ano/ } \\
\text { país }\end{array}$ & Características gerais & $\begin{array}{l}\text { Definição de } \\
\text { sobrevida }\end{array}$ & Variáveis de ajuste & Subtipo tumoral & $\begin{array}{l}\text { Limitações apontadas } \\
\text { pelos autores }\end{array}$ \\
\hline $\begin{array}{l}\text { Sendur et al. } \\
(2016)^{39} \\
\text { Turquia }\end{array}$ & $\begin{array}{l}\text { Coorte retrospectiva } \\
\text { N. }{ }^{\circ} \text { mulheres incluídas: } 826 \\
\text { Mediana de idade: NI } \\
\text { Status menopausal: pré-menopausa } \\
\text { Sobrevida em } 3 \text { anos } \\
\text { Tempo mediano de seguimento: } 37,5 \\
\text { meses } \\
\text { Momento de obtenção do IMC: NI } \\
\text { Forma de obtenção do peso e da altura: NI }\end{array}$ & $\begin{array}{l}\text { SLD: intervalo } \\
\text { de tempo entre } \\
\text { o diagnóstico e a } \\
\text { primeira recorrência } \\
\text { ou morte por qualquer } \\
\text { causa } \\
\text { SG: intervalo de tempo } \\
\text { entre o diagnóstico e } \\
\text { a morte por qualquer } \\
\text { causa }\end{array}$ & Não ajustado & $\begin{array}{l}\text { Luminal (RH+e } \\
\text { HER2 +/-) }\end{array}$ & $\begin{array}{l}\text { Natureza retrospectiva, } \\
\text { ausência de informações para } \\
\text { comparação sobre dose de } \\
\text { quimioterapia entre obesos } \\
\text { e não obesos, ausência } \\
\text { de informações sobre } \\
\text { alteração do peso durante o } \\
\text { seguimento, pequeno tempo } \\
\text { de seguimento, ausência } \\
\text { de análise considerando } \\
\text { comorbidades }\end{array}$ \\
\hline $\begin{array}{l}\text { Liu et al. } \\
(2018)^{34} \\
\text { EUA }\end{array}$ & $\begin{array}{l}\text { Coorte retrospectiva } \\
\text { N. }{ }^{\circ} \text { de mulheres incluídas: } 273 \\
\text { Mediana de idade: } \mathrm{SI} \\
\text { Status menopausal: NI } \\
\text { Sobrevida em } 3 \text { anos } \\
\text { Tempo mediano de seguimento: } 32,6 \\
\text { meses } \\
\text { Momento de obtenção do IMC: mediana } \\
\text { de tempo de } 21 \text { dias após o diagnóstico } \\
\text { Forma de obtenção do peso e da altura: NI }\end{array}$ & $\begin{array}{l}\text { SLD: tempo entre } \\
\text { o diagnóstico e o } \\
\text { primeiro evento } \\
\text { (qualquer metástase } \\
\text { a distância ou local/ } \\
\text { regional, câncer } \\
\text { de mama invasivo } \\
\text { contralateral, qualquer } \\
\text { câncer invasivo } \\
\text { secundário) } \\
\text { SG: tempo entre o } \\
\text { diagnóstico e a morte } \\
\text { por qualquer causa }\end{array}$ & Não ajustado & $\begin{array}{l}\text { Luminal (RE+ e/ou } \\
\text { RP +/HER2-) } \\
\text { HER2 + (RH + /-) } \\
\text { TN (RE-/RP-/HER2-) }\end{array}$ & $\begin{array}{l}\text { Natureza retrospectiva, } \\
\text { pequeno tamanho amostral, } \\
\text { incompleta avaliação do } \\
\text { status menopausal, utilização } \\
\text { de terapia hormonal }\end{array}$ \\
\hline $\begin{array}{l}\text { Martel et al. } \\
(2018)^{33} \\
\text { Itália e centros } \\
\text { afiliados }\end{array}$ & $\begin{array}{l}\text { Coorte retrospectiva } \\
\text { N. }{ }^{0} \text { de mulheres incluídas: } 329 \\
\text { Mediana de idade: NI } \\
\text { Status menopausal: pré e pós-menopausa } \\
\text { Sobrevida em } 3 \text { anos } \\
\text { Tempo mediano de seguimento: } 3 \text { anos } \\
\text { Momento de obtenção do IMC: ao } \\
\text { diagnóstico } \\
\text { Forma de obtenção do peso e da altura: NI }\end{array}$ & $\begin{array}{l}\text { SG: tempo entre a } \\
\text { randomização e a } \\
\text { morte por qualquer } \\
\text { causa }\end{array}$ & \begin{tabular}{|l|} 
Estadiamento IV \\
ao diagnóstico, \\
intervalo livre de \\
doença, status de \\
receptor hormonal e \\
grau histológico
\end{tabular} & HER2 + (RH +/-) & Pequeno tamanho amostral \\
\hline
\end{tabular}

Legendas: NI = não informado; SLD = sobrevida livre de doença; SG = sobrevida global; SRC = Sobrevida relacionada ao câncer; SLP = sobrevida livre de progressão; $\mathrm{TN}$ = triplo-negativo; $\mathrm{RE}$ = receptor para estrogênio; $\mathrm{RP}$ = receptor para progesterona; $\mathrm{RH}$ = receptor hormonal (incluindo RE e RP); HER2 = fator de crescimento epidérmico humano; $\mathrm{IMC}$ = índice de massa corporal; $\mathrm{DP}=$ desvio-padrão.

${ }^{a}$ Considerado HER2 superexpresso nesta revisão, apesar de não haver informação sobre RP.

${ }^{\mathrm{b}}$ Não especificados.

${ }^{c}$ Analisado por tipo de hormonioterapia. Não considerado nesta revisão.

equipamentos e local adequados para a aferição das medidas, além de pessoal treinado. Apesar das facilidades proporcionadas pelo uso do peso e da altura autorreferidos, recomenda-se que o método seja utilizado com cautela, uma vez que as informaçóes podem ser distorcidas pelos participantes, comprometendo a acurácia dos dados. Uma revisão sistemática de literatura, comparando mensuraçôes diretas versus autorreferidas de altura, peso e IMC, verificou tendência à subestimação para peso e IMC, e superestimaçáo para a altura ${ }^{41}$. Uma revisão integrativa examinando a acurácia da altura e do peso autorreferidos, incluindo um total de 35 estudos realizados com mulheres, sendo a altura investigada em $26(\mathrm{n}=39.244)$ e o peso em $34(\mathrm{n}=57.172)$, mostrou que 21 dos 26 estudos revelaram que mulheres superestimam a altura, e que todos os estudos relacionados ao peso reportaram que mulheres o subestimam. Os autores sinalizaram que, apesar de a variação média entre os valores autorreferidos e os aferidos ter sido pequena, um percentual importante de mulheres apresentou grande variação nos valores ${ }^{42}$. Segundo Martins et al. ${ }^{43}$, algumas variáveis, como sexo, idade e situação econômica, devem ser cuidadosamente avaliadas para evitar potenciais vieses de aferição da informação autorreferida de peso e altura. Estudos apontam que a altura tende a ser mais sobrestimada por homens $s^{44-46}$, especialmente em idosos $^{47}$, enquanto o peso tende a ser mais subestimado por mulhere ${ }^{43,47-50}$; e a escolaridade ${ }^{51}$, a renda familiar ${ }^{52} \mathrm{e}$ algumas características corporai ${ }^{53}$ também podem afetar a precisão dessas informaçōes. Indivíduos com baixos níveis socioeconômicos e de escolaridade realizam aferição de peso e altura com menor frequência, em razão da maior dificuldade de acesso a serviços de saúde, de balanças domésticas e de outros locais que possibilitem mediçôes antropométricas. Quando indagados sobre suas medidas, 
informam peso e altura incorretos, frequentemente subestimando o peso e superestimando a altura ${ }^{43,52,53}$. O estudo de Dekkers et al. ${ }^{53}$, realizado em uma populaçáo com sobrepeso ( $\mathrm{n}=1.298)$, mostrou que o peso corporal foi subestimado em $1,4 \mathrm{~kg}(\mathrm{DP} \pm 1,9)$ e a altura superestimada em $0,7 \mathrm{~cm}(\mathrm{DP} \pm 1,5)$, ambos com significância estatística $(\mathrm{p}<0,001)$. Segundo os pesquisadores, as divergências entre as informaçōes e as medidas reais podem ser pelo fato de as pessoas com sobrepeso aferirem suas medidas com menor frequência, não sabendo informar seu peso e altura com precisão. Além disso, consideram que haja influência dos padrôes impostos pela sociedade quanto às caraterísticas corporais, em que ser alto e magro é visto como ideal.

Adicionalmente, fazendo um paralelo com a prática clínica em câncer de mama, questôes importantes devem ser consideradas com relaçáo à escolha do momento para aferição do peso e sua validação: quando realizada após a cirurgia radical, não refletirá a massa corporal total de forma adequada, uma vez que há retirada completa da mama; quando aferido após o início do tratamento quimioterápico, seja neoadjuvante ou adjuvante, poderá estar sobrestimado pelo acúmulo de retenção hídrica em virtude do uso de corticoides comumente utilizados para manejo dos sintomas durante a quimioterapia; quando aferido meses depois do diagnóstico, independentemente de ter sido realizado qualquer tipo de tratamento, o peso corporal pode estar alterado, seja por intervenção dietética orientada por profissionais de saúde após o diagnóstico, seja por alteração natural da alimentação posterior à ciência da doença, que pode ser no sentido do aumento ou da redução do consumo habitual. Assim, sendo o IMC uma variável independente em estudos que buscam investigar sua associaçáo com a recidiva da doença ou com a mortalidade, aconselha-se que os dados antropométricos, peso e altura, sejam obtidos por aferição direta realizada com equipamentos e técnica adequados, por pessoal treinado e no momento adequado; além disso, ressalta-se a importância da presença de informaçôes detalhadas e claras nas publicaçóes, pois este pode ser um diferencial para análise agrupada dos dados, uma vez que poderá determinar heterogeneidade entre os estudos.

Conforme relatório da $\mathrm{OMS}^{40}$, a obesidade é uma condição de acúmulo excessivo de gordura na forma de tecido adiposo, onde sua extensão pode afetar adversamente a saúde, e recomenda a classificação da obesidade por intermédio do IMC, sendo a obesidade diagnosticada quando este é igual ou superior a $30 \mathrm{~kg} / \mathrm{m}^{2}$. É um indicador de saúde aceito e utilizado mundialmente como um indicativo indireto de adiposidade corporal. Embora não permita distinguir massa adiposa de massa magra, não reflete corretamente a distribuição da gordura corporal. Recentemente, tem-se observado que a distribuição de gordura corporal é mais preditiva para a saúde, sendo a gordura visceral um fator de risco potencial para algumas doenças relacionadas às desordens metabólicas ${ }^{40,54}$, entre elas, o câncer de mama. Considerando a importância da adiposidade visceral como indutora de desordens metabólicas, a OMS recomenda, além da aferição do IMC, mensurar a circunferência da cintura como um indicador de distribuição de adiposidade corporal e, consequentemente, de risco para complicaçóes metabólicas ${ }^{40}$. Assim, medidas de estimativa da gordura visceral devem ser incorporadas na avaliação de sobrepeso e obesidade, especialmente em estudos que buscam correlacionar a adiposidade corporal com o risco de complicaçôes ou de morte por doenças.

No que se refere aos subtipos tumorais, foram identificados 17 estudos que incluíram na análise o subtipo triplo-negativo $(\mathrm{TN})^{14,19-21,24-27,29-32,34-38}, 11$ incluíram o subtipo luminal e suas variaçôes ${ }^{14,18-20,23,26,28,32,35,38,39}$ e seis HER2 superexpressos associados a RH negativo ${ }^{14,18,26,32,35,38}$. Cinco estudos realizaram análise considerando apenas o status de HER2, incluindo os casos HER2 positivos independente do status de $\mathrm{RH}^{19,20,22,33,34}$, não sendo adotadas as classificaçôes tradicionalmente utilizadas (Tabela 1).

Até o final da década de 1990, a classificação do carcinoma de mama era realizada considerando suas características morfológicas. Entretanto, foi observado que pacientes com características clínicas e patológicas semelhantes apresentavam evolução e resposta ao tratamento de forma diferenciada, exibindo prognósticos distintos. Posteriormente, foram identificados subtipos moleculares com diferentes prognósticos, revelando ser o câncer de mama uma doença heterogênea e que tais subtipos deveriam ser considerados no diagnóstico e planejamento terapêutico. Inicialmente, a classificação proposta para determinar aqueles subtipos foi baseada em microarrays de ácido desoxirribonucleico (do inglês deoxyribonucleic acid - DNA) e padrōes de expressão gênica; entretanto, apesar de esta ser considerada como padrão-ouro para tal determinação, sua complexidade e alto custo limitam sua utilização de rotina. Em 2011, durante a 12th St Gallen International Breast Cancer Conference Expert Panel, a classificação por subtipo clinicopatológico, realizada por imuno-histoquímica e hibridização fluorescente in situ (FISH) e que se aproxima daquela baseada em microarrays de DNA e padróes de expressão gênica, porém mais simples e de menor custo, foi adotada para as deliberaçóes sobre estratégias terapêuticas, sendo considerado o uso dos RE, RP, HER2 e do antígeno Ki67, um importante marcador de proliferação celular, e seus pontos de corte para a classificação dos subtipos tumorais. Posteriormente, algumas alteraçóes para classificação dos subtipos foram adotadas, sustentando o 
uso dos mesmos marcadores tumorais ${ }^{55-57}$. Nesse contexto, os estudos incluídos na presente revisão apresentaram diferentes classificaçóes de subtipos tumorais, em particular para os luminais, dificultando a comparação de seus resultados. Por esse motivo, os subtipos luminais foram analisados e discutidos de forma conjunta. Já os estudos com positividade para HER2 que não adotaram a classificação por subtipos propostas pela literatura foram apresentados separadamente.

Os subtipos luminais são assim denominados por se originarem nas células epiteliais dos lúmens ducto-lobulares, naturalmente ricas em RE. Sáo subdivididos em subtipo luminal A e luminal B. No luminal A, há negatividade para HER2, com presença de RE e RP em grande quantidade de células, e a análise de Ki67 mostra ritmo de proliferaçáo baixo. Corresponde a cerca de $50 \%$ a $60 \%$ dos casos de câncer de mama e são bastante sensíveis à hormonioterapia. O subtipo luminal B também se origina em células epiteliais luminais ricas em RE. Os $\mathrm{RP}$ podem estar presentes em alta ou em baixa proporção de células, o HER2 pode ser detectado e a análise de Ki67 mostra ritmo de proliferação mais elevado. Representa $20 \%$ a $30 \%$ dos casos de carcinoma de mama. Esse subtipo também é sensível à hormonioterapia e, caso apresente positividade para HER2, o trastuzumab pode ser indicado ${ }^{58,59}$. Entre os dez estudos que estimaram o impacto do IMC na sobrevida de mulheres com câncer de mama subtipo luminal considerando a análise de risco, seis demostraram associação inversa entre o IMC e um ou mais tipos de sobrevida (SLD, SG e SRC) ${ }^{14,20,23,32,35,38}$. Dos três estudos que analisaram diferenças nas curvas de sobrevida exibidas nas diferentes categorias de IMC, um mostrou diferença entre as curvas de $\mathrm{SLD}^{20}$ e um entre as curvas de $S^{39}$. Quatro estudos não apresentaram resultados estatisticamente significativos em nenhuma das análises realizadas ${ }^{18,19,26,28}$ (Tabela 2).

Tabela 2. Efeito do índice de massa corporal na sobrevida de mulheres com câncer de mama luminal

\begin{tabular}{|c|c|c|c|c|c|c|c|c|c|c|}
\hline \multirow{3}{*}{$\begin{array}{c}\text { Primeiro autor/ } \\
\text { ano/país }\end{array}$} & \multirow{3}{*}{ Pontos de corte para IMC } & \multicolumn{6}{|c|}{ Hazard ratio } & \multirow{2}{*}{\multicolumn{3}{|c|}{$\begin{array}{l}\text { Kaplan-Meier } \\
\text { Log-rank test }\end{array}$}} \\
\hline & & \multicolumn{2}{|c|}{ SLD } & \multicolumn{2}{|c|}{ SG } & \multicolumn{2}{|c|}{ SRC } & & & \\
\hline & & HR & IC $95 \%$ & HR & IC $95 \%$ & HR & IC 95\% & SLD & SG & SRC \\
\hline $\begin{array}{l}\text { Sparano et al. } \\
(2012)^{a 14} \\
\text { EUA }\end{array}$ & $\begin{array}{l}\text { RH }+/ \text { HER2- ou desconhecido } \\
<30 \mathrm{~kg} / \mathrm{m}^{2} \\
\geq 30 \mathrm{~kg} / \mathrm{m}^{2}\end{array}$ & $\begin{array}{l}1,00 \\
1,24\end{array}$ & $1,06-1,46$ & $\begin{array}{l}1,00 \\
1,37\end{array}$ & $1,13-1,67$ & $\begin{array}{l}1,00 \\
1,40\end{array}$ & $1,11-1,76$ & - & - & - \\
\hline $\begin{array}{l}\text { Mazzarella et al. } \\
(2013)^{b} 18 \\
\text { ltália }\end{array}$ & $\begin{array}{l}\text { RE }+/ \text { HER2 }+ \\
<25 \mathrm{~kg} / \mathrm{m}^{2} \\
25,0-29,9 \mathrm{~kg} / \mathrm{m}^{2} \\
\geq 30 \mathrm{~kg} / \mathrm{m}^{2}\end{array}$ & $\begin{array}{l}1,00 \\
0,88 \\
0,75\end{array}$ & $\begin{array}{l}0,63-1,23 \\
0,43-1,31\end{array}$ & $\begin{array}{l}1,00 \\
0,77 \\
1,05\end{array}$ & $\begin{array}{l}0,46-1,26 \\
0,53-2,09\end{array}$ & - & - & $p=0,55^{\S}$ & $\mathrm{p}=0,85^{\S}$ & \\
\hline $\begin{array}{l}\text { Pajares et al. } \\
(2013)^{119} \\
\text { Espanha }\end{array}$ & $\begin{array}{l}\text { RE e/ou RP+/HER2- } \\
<25,0 \mathrm{~kg} / \mathrm{m}^{2} \\
\geq 35 \mathrm{~kg} / \mathrm{m}^{2}\end{array}$ & $\begin{array}{l}1,0 \\
1,1\end{array}$ & $0,8-1,6$ & $\begin{array}{l}1,0 \\
1,3\end{array}$ & $0,9-1,8$ & $\begin{array}{l}1,0 \\
1,3\end{array}$ & $0,9-2,0$ & - & - & - \\
\hline $\begin{array}{l}\text { Turkoz et al. } \\
(2013)^{\mathrm{d} 26} \\
\text { Turquia }\end{array}$ & $\begin{array}{l}\text { RE e/ou RP+/HER2- } \\
18,5-24,9 \mathrm{~kg} / \mathrm{m}^{2} \\
\geq 30 \mathrm{~kg} / \mathrm{m}^{2}\end{array}$ & - & - & $\begin{array}{l}1,00 \\
1,5\end{array}$ & $1,0-2,2$ & - & - & - & - & - \\
\hline $\begin{array}{l}\text { Robinson et al. } \\
(2014)^{\text {e } 23} \\
\text { Austrália }\end{array}$ & $\begin{array}{l}\text { RH }+/ \text { HER2- } \\
25,0-29,9 \mathrm{~kg} / \mathrm{m}^{2} \\
30-39,9 \mathrm{~kg} / \mathrm{m}^{2}\end{array}$ & $\begin{array}{l}1,00 \\
1,71\end{array}$ & $1,12-2,62$ & - & - & - & - & - & - & - \\
\hline $\begin{array}{l}\text { Xiao et al. } \\
(2014)^{f 28} \\
\text { China }\end{array}$ & $\begin{array}{l}\text { Luminal A } \\
<25,0 \mathrm{~kg} / \mathrm{m}^{2} \\
25,0-30,0 \mathrm{~kg} / \mathrm{m}^{2} \\
\geq 30,0 \mathrm{~kg} / \mathrm{m}^{2} \\
\\
\text { Luminal B } \\
\text { (Ki67 elevado) } \\
<25,0 \mathrm{~kg} / \mathrm{m}^{2} \\
25,0-30,0 \mathrm{~kg} / \mathrm{m}^{2} \\
\geq 30,0 \mathrm{~kg} / \mathrm{m}^{2} \\
\\
\text { Luminal B } \\
\text { (HER2-/neu+) } \\
<25,0 \mathrm{~kg} / \mathrm{m}^{2} \\
25,0-30,0 \mathrm{~kg} / \mathrm{m}^{2} \\
\geq 30,0 \mathrm{~kg} / \mathrm{m}^{2}\end{array}$ & - & - & - & - & $\begin{array}{c}1,00 \\
0,743 \\
0,761 \\
\\
1,00 \\
0,854 \\
1,043 \\
\\
1,00 \\
0,939 \\
1,227\end{array}$ & $\begin{array}{l}0,491-1,124 \\
0,522-1,109 \\
0,698-1,046 \\
0,846-1,286 \\
0,680-1,295 \\
0,890-1,692\end{array}$ & - & - & - \\
\hline
\end{tabular}


Tabela 2. continuação

\begin{tabular}{|c|c|c|c|c|c|c|c|c|c|c|}
\hline \multirow{3}{*}{$\begin{array}{c}\text { Primeiro autor/ } \\
\text { ano/país }\end{array}$} & \multirow{3}{*}{ Pontos de corte para IMC } & \multicolumn{6}{|c|}{ Hazard ratio } & \multirow{2}{*}{\multicolumn{3}{|c|}{$\begin{array}{l}\text { Kaplan-Meier } \\
\text { Log-rank test }\end{array}$}} \\
\hline & & \multicolumn{2}{|c|}{ SLD } & \multicolumn{2}{|c|}{ SG } & \multicolumn{2}{|c|}{ SRC } & & & \\
\hline & & HR & IC $95 \%$ & HR & IC $95 \%$ & HR & IC $95 \%$ & SLD & SG & SRC \\
\hline $\begin{array}{l}\text { Jeon et al. } \\
(2015)^{g^{32}} \\
\text { Coreia }\end{array}$ & $\begin{array}{l}\text { RE e/ou RP + e HER2- } \\
<18,5 \mathrm{~kg} / \mathrm{m}^{2} \\
18,5-24,9 \mathrm{~kg} / \mathrm{m}^{2} \\
25,0-29,9 \mathrm{~kg} / \mathrm{m}^{2} \\
\geq 30 \mathrm{~kg} / \mathrm{m}^{2} \\
\\
\mathrm{RE} \text { e } / \text { ou } \mathrm{RP}+\text { e HER2+ } \\
<18,5 \mathrm{~kg} / \mathrm{m}^{2} \\
18,5-24,9 \mathrm{~kg} / \mathrm{m}^{2} \\
25-29,9 \mathrm{~kg} / \mathrm{m}^{2} \\
\geq 30 \mathrm{~kg} / \mathrm{m}^{2}\end{array}$ & - & - & $\begin{array}{l}1,26 \\
1,00 \\
1,32 \\
1,48 \\
\\
\\
1,07 \\
1,00 \\
1,02 \\
0,94 \\
\end{array}$ & $\begin{array}{l}0,94-1,69 \\
1,18-1,48 \\
1,18-1,85 \\
0,63-1,83 \\
0,81-1,28 \\
0,55-1,61 \\
\end{array}$ & $\begin{array}{l}1,24 \\
1,00 \\
1,30 \\
1,31 \\
\\
\\
0,61 \\
1,00 \\
1,18 \\
0,62 \\
\end{array}$ & $\begin{array}{l}0,85-1,82 \\
0,96-1,76 \\
1,13-1,52 \\
0,25-1,48 \\
0,90-1,55 \\
0,27-1,39 \\
\end{array}$ & - & - & - \\
\hline $\begin{array}{l}\text { Ligibel et al. } \\
(2015)^{\mathrm{h} 35} \\
\text { EUA }\end{array}$ & $\begin{array}{l}\text { Luminal A } \\
\text { Para cada } 5 \text { unidades de } \\
\text { aumento de IMC } \\
\text { Luminal B } \\
\text { Para cada } 5 \text { unidades de } \\
\text { aumento de IMC }\end{array}$ & 1,23 & $\begin{array}{l}1,08-1,40 \\
0,87-1,16\end{array}$ & - & - & - & - & - & - & - \\
\hline $\begin{array}{l}\text { Widschwendter et } \\
\text { al. }(2015)^{i 20} \\
\text { Alemanha }\end{array}$ & $\begin{array}{l}\text { Luminal A like } \\
<25,0 \mathrm{~kg} / \mathrm{m}^{2} \\
25,0-29,9 \mathrm{~kg} / \mathrm{m}^{2} \\
30,0-34,9 \mathrm{~kg} / \mathrm{m}^{2} \\
35,0-39,9 \mathrm{~kg} / \mathrm{m}^{2} \\
\geq 30 \mathrm{~kg} / \mathrm{m}^{2} \\
\text { Luminal B } \mathrm{like} \\
<25,0 \mathrm{~kg} / \mathrm{m}^{2} \\
25,0-29,9 \mathrm{~kg} / \mathrm{m}^{2} \\
30,0-34,9 \mathrm{~kg} / \mathrm{m}^{2} \\
35,0-39,9 \mathrm{~kg} / \mathrm{m}^{2} \\
\geq 30 \mathrm{~kg} / \mathrm{m}^{2}\end{array}$ & $\begin{array}{l}1,00 \\
1,21 \\
1,10 \\
1,42 \\
0,82 \\
\\
\\
\\
\\
1,00 \\
1,18 \\
1,46 \\
0,76 \\
3,32\end{array}$ & $\begin{array}{l}0,81-1,82 \\
0,66-1,83 \\
0,65-3,09 \\
0,11-6,06 \\
\\
0,72-1,93 \\
0,78-2,74 \\
0,29-2,00 \\
1,17-9,46\end{array}$ & $\begin{array}{l}1,00 \\
0,86 \\
1,32 \\
1,72 \\
1,51 \\
\\
\\
\\
\\
\\
1,00 \\
0,87 \\
1,29 \\
0,58 \\
2,84\end{array}$ & $\begin{array}{l}0,48-1,52 \\
0,71-2,47 \\
0,69-4,30 \\
0,20-11,42 \\
\\
\\
0,44-1,75 \\
0,55-3,00 \\
0,17-2,07 \\
0,71-11,40\end{array}$ & - & - & $\mathrm{p}=0,45^{*}$ & $p=0,25^{*}$ & - \\
\hline $\begin{array}{l}\text { Kawai et al. } \\
(2016)^{i 38} \\
\text { Japão }\end{array}$ & $\begin{array}{l}\text { Luminal A } \\
<18,5 \mathrm{~kg} / \mathrm{m}^{2} \\
18,5-21,7 \mathrm{~kg} / \mathrm{m}^{2} \\
21,8-24,0 \mathrm{~kg} / \mathrm{m}^{2} \\
25,0-30,0 \mathrm{~kg} / \mathrm{m}^{2} \\
\geq 30 \mathrm{~kg} / \mathrm{m}^{2} \\
\\
\text { Luminal B } \\
<18,5 \mathrm{~kg} / \mathrm{m}^{2} \\
18,5-21,7 \mathrm{~kg} / \mathrm{m}^{2} \\
21,8-24,0 \mathrm{~kg} / \mathrm{m}^{2} \\
25,0-30,0 \mathrm{~kg} / \mathrm{m}^{2} \\
\geq 30 \mathrm{~kg} / \mathrm{m}^{2}\end{array}$ & $\begin{array}{l}1,24 \\
1,00 \\
1,11 \\
1,07 \\
1,23 \\
\\
\\
\\
0,97 \\
1,00 \\
1,01 \\
0,87 \\
1,16\end{array}$ & $\begin{array}{l}0,93-1,64 \\
0,92-1,33 \\
0,87-1,31 \\
0,90-1,68 \\
0,70-1,37 \\
0,83-1,24 \\
0,68-1,12 \\
0,77-1,75\end{array}$ & - & - & $\begin{array}{l}1,39 \\
1,00 \\
1,05 \\
1,27 \\
1,64 \\
\\
\\
\\
1,32 \\
1,00 \\
1,07 \\
1,14 \\
2,59\end{array}$ & $\begin{array}{l}0,77-2,49 \\
0,71-1,56 \\
0,84-1,92 \\
0,93-2,90 \\
\\
0,75-2,35 \\
0,73-1,54 \\
0,75-1,74 \\
1,51-4,43\end{array}$ & - & - & - \\
\hline $\begin{array}{l}\text { Sendur et al. } \\
(2016)^{\mathrm{k} 39} \\
\text { Turquia }\end{array}$ & $\begin{array}{l}\text { RH+ e HER2+/- } \\
18,5-24,9 \mathrm{~kg} / \mathrm{m}^{2} \\
\geq 25,0 \mathrm{~kg} / \mathrm{m}^{2}\end{array}$ & - & - & - & - & - & - & $p=0,39^{£}$ & $p=0,03^{f}$ & \\
\hline
\end{tabular}

Legendas: $\mathrm{IMC}=$ índice de massa corporal; $\mathrm{SLD}=$ sobrevida livre de doença; $\mathrm{SG}=$ sobrevida global; $\mathrm{SRC}=$ sobrevida relacionada ao câncer; $\mathrm{HR}=$ hazard ratio; $\mathrm{IC}=$ intervalo de confiança; $\mathrm{RE}$ = receptor para estrogênio; $\mathrm{RP}$ = receptor para progesterona; $\mathrm{RH}$ = receptor hormonal (incluindo RE e RP); HER2 = fator de crescimento epidérmico humano.

${ }^{2}$ Ajustado para idade, raça, status menopausal, tamanho tumoral, n. ${ }^{\circ}$ de nódulo linfático axilar positivo, tipo de cirurgia, radioterapia, quimioterapia e hormonioterapia (dependendo do braco de tratamento do ensaio clínico).

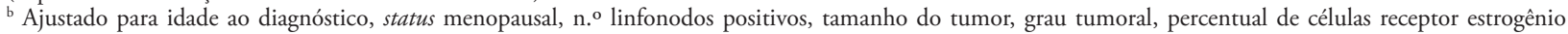
positivas, invasão perivascular e tipo de cirurgia.

'Ajustado para idade, status menopausal, tamanho tumoral, status nodal, grau histológico, status de RH, status de HER2, tipo de cirurgia, subtratamento global, estudo (incluindo status nodal).

d Ajustado para idade, tamanho tumoral, envolvimento nodal, grau histológico, invasão linfovascular e perineural, extensão extracapsular, status hormonal.

c, Variáveis de ajuste năo informadas.

${ }^{g}$ Ajustado para idade, tamanho tumoral, status nodal, grau histológico, método cirúrgico, tratamento adjuvante, status de RE e RP e expressão de HER2.

h,k Năo ajustado.

i Ajustado para idade, tamanho tumoral, status nodal, grau tumoral, tipo histológico, status de receptor hormonal, status de HER2, status menopausal, tipo de cirurgia, tratamento quimioterápico, terapia hormonal e subtratamento quimioterápico.

¡ Ajustado para idade, região de residência, método de detecçâo, história familiar do câncer de mama, estágio tumoral, radioterapia, quimioterapia, terapia endócrina, status menopausal e ano de registro.

${ }^{\$}$ Tempo de sobrevida em 5 anos.

¥ Tempo de sobrevida não informado.

${ }^{E}$ Tempo de sobrevida em 3 anos. 
O subtipo HER2 superexpresso, assim definido quando há amplificação genética ou elevada expressão da oncoproteína HER2 e negatividade para RH, acomete aproximadamente $15 \%$ a $20 \%$ dos pacientes com carcinoma de mama invasivo ${ }^{58-60}$. O HER2 pertence à família dos receptores de crescimento. Codifica uma proteína de membrana que faz com que as células tumorais se desenvolvam mais rápido e aumentem a sua capacidade de duplicação, tornando os tumores mais agressivos; assim, sua expressão é associada à maior agressividade biológica do tumor e à resistência a alguns tipos de tratamento ${ }^{61}$. É o subtipo que representa o segundo pior prognóstico quando comparado aos demais ${ }^{62}$. Dos seis estudos que realizaram análise com o subtipo HER2 superexpresso ${ }^{14,18,26,32,35,38 \text {, }}$ dois mostraram associação inversa entre IMC e sobrevida, com aumento no risco de mortalidade global para mulheres obesas $^{18,26}$. Resultado diferente foi observado no estudo de Kawai et al..$^{38}$, que observou reduçáo no risco de morte relacionada ao câncer para mulheres com sobrepeso ${ }^{38}$. Já no estudo de Jeon et al. ${ }^{32}$, divergindo com todos os outros resultados encontrados, o aumento no risco de mortalidade global foi identificado em mulheres com baixo peso; este mesmo estudo foi o único que apresentou aumento no risco de morte por câncer, da mesma forma, para o grupo de mulheres com baixo peso ${ }^{32}$. Curvas de SLD e de SG entre os grupos de IMC foram comparadas no estudo de Mazzarella et al. ${ }^{18}$, evidenciando diferença estatisticamente significativa entre as curvas de $\mathrm{SG}^{18}$ (Tabela 3).

Tabela 3. Efeito do índice de massa corporal na sobrevida de mulheres com câncer de mama HER2 superexpresso e HER2 positivo (receptor hormonal positivo ou negativo)

\begin{tabular}{|c|c|c|c|c|c|c|c|c|c|c|}
\hline \multirow{3}{*}{$\begin{array}{c}\text { Primeiro autor/ } \\
\text { ano/país }\end{array}$} & \multirow{3}{*}{ Pontos de corte para IMC } & \multicolumn{6}{|c|}{ Hazard ratio } & \multirow{2}{*}{\multicolumn{3}{|c|}{$\begin{array}{l}\text { Kaplan-Meier } \\
\text { Log-rank test }\end{array}$}} \\
\hline & & \multicolumn{2}{|c|}{ SLD } & \multicolumn{2}{|c|}{ SG } & \multicolumn{2}{|c|}{ SRC } & & & \\
\hline & & HR & IC $95 \%$ & HR & IC $95 \%$ & HR & IC $95 \%$ & SLD & SG & SRC \\
\hline \multicolumn{11}{|c|}{ Subtipo HER2 superexpresso } \\
\hline $\begin{array}{l}\text { Sparano et al. } \\
(2012)^{a 14} \\
\text { EUA }\end{array}$ & $\begin{array}{l}<30,0 \mathrm{~kg} / \mathrm{m}^{2} \\
\geq 30,0 \mathrm{~kg} / \mathrm{m}^{2}\end{array}$ & $\begin{array}{l}1,00 \\
1,06\end{array}$ & $0,82-1,38$ & $\begin{array}{l}1,00 \\
0,99\end{array}$ & $\begin{array}{c}1,00 \\
0,73-1,34\end{array}$ & $\begin{array}{l}1,00 \\
1,00\end{array}$ & $0,71-1,40$ & - & - & - \\
\hline $\begin{array}{l}\text { Mazzarella et al. } \\
(2013)^{b} 18 \\
\text { Itália }\end{array}$ & $\begin{array}{l}<25,0 \mathrm{~kg} / \mathrm{m}^{2} \\
25,0-29,9 \mathrm{~kg} / \mathrm{m}^{2} \\
\geq 30,0 \mathrm{~kg} / \mathrm{m}^{2}\end{array}$ & $\begin{array}{l}1,00 \\
0,99 \\
1,34\end{array}$ & $\begin{array}{c}0,7-1,39 \\
0,84-2,13\end{array}$ & $\begin{array}{l}1,00 \\
1,16 \\
1,79\end{array}$ & $\begin{array}{l}0,75-1,79 \\
1,03-3,10\end{array}$ & - & - & $p=0,17^{\S}$ & $\mathrm{p}=0,04 \S$ & \\
\hline $\begin{array}{l}\text { Turkoz et al. } \\
(2013)^{126} \\
\text { Turquia }\end{array}$ & $\begin{array}{l}18,5-24,9 \\
\geq 30,0 \mathrm{~kg} / \mathrm{m}^{2}\end{array}$ & - & - & $\begin{array}{l}1,00 \\
1,4\end{array}$ & $1,1-2,1$ & - & - & - & - & - \\
\hline $\begin{array}{l}\text { Jeon et al. } \\
(2015)^{\mathrm{d} 32} \\
\text { Careia }\end{array}$ & $\begin{array}{l}<18,5 \mathrm{~kg} / \mathrm{m}^{2} \\
18,5-24,9 \mathrm{~kg} / \mathrm{m}^{2} \\
25-29,9 \mathrm{~kg} / \mathrm{m}^{2} \\
\geq 30,0 \mathrm{~kg} / \mathrm{m}^{2}\end{array}$ & - & - & $\begin{array}{l}1,67 \\
1,00 \\
0,94 \\
1,18 \\
\end{array}$ & $\begin{array}{l}1,12-2,47 \\
0,77-1,14 \\
0,79-1,76\end{array}$ & $\begin{array}{l}1,79 \\
1,00 \\
0,93 \\
1,16\end{array}$ & $\begin{array}{l}1,11-2,90 \\
0,73-1,19 \\
0,70-1,93 \\
\end{array}$ & - & - & - \\
\hline $\begin{array}{l}\text { Ligibel et al. } \\
(2015)^{\text {e35 }}\end{array}$ & $\begin{array}{l}\text { Para cada } 5 \text { unidades de } \\
\text { aumento de IMC }\end{array}$ & 1,10 & $0,97-1,26$ & - & - & - & - & - & - & - \\
\hline $\begin{array}{l}\text { Kawai et al. } \\
(2016)^{\dagger 38} \\
\text { Japão }\end{array}$ & $\begin{array}{l}<18,5 \mathrm{~kg} / \mathrm{m} 2 \\
18,5-21,7 \mathrm{~kg} / \mathrm{m} 2 \\
21,8-24,0 \mathrm{~kg} / \mathrm{m} 2 \\
25,0-30,0 \mathrm{~kg} / \mathrm{m} 2 \\
\geq 30,0 \mathrm{~kg} / \mathrm{m}^{2}\end{array}$ & $\begin{array}{l}0,95 \\
1,00 \\
0,93 \\
0,74 \\
1,24\end{array}$ & $\begin{array}{l}0,61-1,47 \\
0,72-1,22 \\
0,52-1,05 \\
0,68-2,26\end{array}$ & - & - & $\begin{array}{l}0,99 \\
1,00 \\
0,73 \\
0,43 \\
1,53\end{array}$ & $\begin{array}{l}0,52-1,89 \\
0,48-1,10 \\
0,23-0,80 \\
0,68-3,42\end{array}$ & - & - & - \\
\hline \multicolumn{11}{|c|}{ HER2 positivo (RH positivo ou negativo) } \\
\hline $\begin{array}{l}\text { Crozier et al. } \\
(2013)^{922} \\
\text { EUA }\end{array}$ & $\begin{array}{l}\text { Grupos A, B e C } \S \\
<25,0 \mathrm{~kg} / \mathrm{m}^{2} \\
25,0-29,9 \mathrm{~kg} / \mathrm{m}^{2} \\
\geq 30,0 \mathrm{~kg} / \mathrm{m}^{2} \\
\text { Grupo A } \\
<25,0 \mathrm{~kg} / \mathrm{m}^{2} \\
25,0-29,9 \mathrm{~kg} / \mathrm{m}^{2} \\
\geq 30,0 \mathrm{~kg} / \mathrm{m}^{2} \\
\text { Grupo B } \\
<25 \mathrm{~kg} / \mathrm{m}^{2} \\
25,0-29,9 \mathrm{~kg} / \mathrm{m}^{2} \\
\geq 30,0 \mathrm{~kg} / \mathrm{m}^{2} \\
\\
\text { Grupo C } \\
<25,0 \mathrm{~kg} / \mathrm{m}^{2} \\
25,0-29,9 \mathrm{~kg} / \mathrm{m}^{2} \\
\geq 30,0 \mathrm{~kg} / \mathrm{m}^{2}\end{array}$ & $\begin{array}{l}1,00 \\
1,30 \\
1,31 \\
\\
1,00 \\
1,20 \\
1,11 \\
\\
1,00 \\
1,40 \\
1,42 \\
\\
1,00 \\
1,17 \\
1,23\end{array}$ & $\begin{array}{l}1,06-1,61 \\
1,07-1,59\end{array}$ & - & - & - & - & $\begin{array}{c}\text { DND } \\
p=0,29 \S \\
p=0,11^{\S} \\
p=0,67 \S\end{array}$ & - & - \\
\hline
\end{tabular}


Tabela 3. continuação

\begin{tabular}{|c|c|c|c|c|c|c|c|c|c|c|}
\hline \multirow{3}{*}{$\begin{array}{c}\text { Primeiro autor/ } \\
\text { ano/país }\end{array}$} & \multirow{3}{*}{ Pontos de corte para IMC } & \multicolumn{6}{|c|}{ Hazard ratio } & \multirow{2}{*}{\multicolumn{3}{|c|}{$\begin{array}{l}\text { Kaplan-Meier } \\
\text { Log-rank test }\end{array}$}} \\
\hline & & \multicolumn{2}{|c|}{ SLD } & \multicolumn{2}{|c|}{ SG } & \multicolumn{2}{|c|}{ SRC } & & & \\
\hline & & HR & IC 95\% & HR & IC 95\% & HR & IC 95\% & SLD & SG & SRC \\
\hline $\begin{array}{l}\text { Pajares et al. } \\
(2013)^{\mathrm{h}} 19 \\
\text { Espanha }\end{array}$ & $\begin{array}{l}<25,0 \mathrm{~kg} / \mathrm{m}^{2} \\
\geq 35,0 \mathrm{~kg} / \mathrm{m}^{2}\end{array}$ & $\begin{array}{l}1,0 \\
1,2\end{array}$ & $0,7-2,1$ & $\begin{array}{l}1,0 \\
1,4\end{array}$ & $0,8-2,5$ & $\begin{array}{l}1,0 \\
1,5\end{array}$ & $0,8-2,8$ & & & - \\
\hline $\begin{array}{l}\text { Widschwendter et } \\
\text { al. }(2015)^{i 20} \\
\text { Alemanha }\end{array}$ & $\begin{array}{l}<25,0 \mathrm{~kg} / \mathrm{m}^{2} \\
25,0-29,9 \mathrm{~kg} / \mathrm{m}^{2} \\
30,0-34,9 \mathrm{~kg} / \mathrm{m}^{2} \\
35,0-39,9 \mathrm{~kg} / \mathrm{m}^{2} \\
\geq 30,0 \mathrm{~kg} / \mathrm{m}^{2}\end{array}$ & $\begin{array}{l}1,00 \\
1,08 \\
0,81 \\
1,09 \\
3,28\end{array}$ & $\begin{array}{l}0,68-1,69 \\
0,44-1,50 \\
0,43-2,79 \\
1,14-9,48\end{array}$ & $\begin{array}{l}1,00 \\
0,86 \\
0,82 \\
1,36 \\
2,78\end{array}$ & $\begin{array}{l}0,46-1,62 \\
0,37-1,80 \\
0,43-4,35 \\
0,75-10,34\end{array}$ & - & - & $p=0,02$ & $p=0,01$ & - \\
\hline $\begin{array}{l}\text { Liv et al. } \\
(2018)^{i 34} \\
\text { EUA }\end{array}$ & $\begin{array}{l}<30,0 \mathrm{~kg} / \mathrm{m}^{2} \\
\geq 30,0 \mathrm{~kg} / \mathrm{m}^{2}\end{array}$ & $\begin{array}{c}1,0 \\
3,37\end{array}$ & $0,97-11,72$ & $\begin{array}{c}1,0 \\
1,35\end{array}$ & $0,22-8,19$ & - & - & & & - \\
\hline $\begin{array}{l}\text { Martel et al. } \\
(2018)^{k^{33}}\end{array}$ & $\begin{array}{l}<25,0 \mathrm{~kg} / \mathrm{m}^{2} \\
\geq 25,0 \mathrm{~kg} / \mathrm{m}^{2}\end{array}$ & & & $\begin{array}{l}1,0 \\
0,88\end{array}$ & $0,59-1,31$ & - & - & $p=0,69 £$ & $p=0,77 £$ & - \\
\hline
\end{tabular}

Legendas: $\mathrm{IMC}=$ índice de massa corporal; $\mathrm{SLD}=$ sobrevida livre de doença; $\mathrm{SG}=$ sobrevida global; $\mathrm{SRC}=$ sobrevida relacionada ao câncer; HR = hazard ratio; $\mathrm{IC}=$ intervalo de confiança; $\mathrm{RH}$ = receptor hormonal (incluindo RE e RP); HER2 = fator de crescimento epidérmico humano; DND = dados nấo demonstrados. ${ }^{\S}$ Grupos de tratamento quimioterápico.

a Ajustado para idade, raça, status menopausal, tamanho tumoral, n. ${ }^{\circ}$ de nódulo linfático axilar positivo, tipo de cirurgia, radioterapia, quimioterapia e hormonioterapia (dependendo do braço de tratamento do ensaio clínico).

${ }^{\text {b }}$ Ajustado para idade ao diagnóstico, status menopausal, número de linfonodos positivos, tamanho do tumor, grau tumoral, percentual de células receptor estrogênio positivas, invasão perivascular e tipo de cirurgia.

c Ajustado para idade, tamanho tumoral, envolvimento nodal, grau histológico, invasão linfovascular e perineural, extensão extracapsular, status hormonal.

d Ajustado para idade, tamanho tumoral, status nodal, grau histológico, método cirúrgico, tratamento adjuvante, status de RE e RP e expressão de HER2.

c, j Não ajustado.

${ }^{\mathrm{f}}$ Ajustado para idade, região de residência, método de detecção, história familiar do câncer de mama, estágio tumoral, radioterapia, quimioterapia, terapia endócrina, status menopausal e ano de registro.

g Ajustado para idade e raça.

${ }^{\text {h }}$ Ajustado para idade, status menopausal, tamanho tumoral, status nodal, grau histológico, status de RH, status de HER2, tipo de cirurgia, subtratamento global, estudo (incluindo status nodal).

i Ajustado para idade, tamanho tumoral, status nodal, grau tumoral, tipo histológico, status de receptor hormonal, status de HER2, status menopausal, tipo de cirurgia, tratamento quimioterápico, terapia hormonal e subtratamento quimioterápico.

${ }^{\mathrm{k}}$ Ajustado para estadiamento IV ao diagnóstico, intervalo livre de doença, status de receptor hormonal e grau histológico.

\$Tempo de sobrevida em 5 anos.

¥ Tempo de sobrevida nấo informado.

${ }^{£}$ Tempo de sobrevida em 3 anos.

Cinco estudos analisaram HER2 positivo independente do status de RH do tumor. Dois deles apresentaram aumento no risco de recorrência da doenç ${ }^{20,22}$; no estudo de Crozier et al..$^{22}$, o aumento no risco de recorrência para os grupos de mulheres com sobrepeso e obesidade foi observado na análise, considerando toda a populaçáo de estudo; entretanto, quando a análise foi estratificada por tipo de tratamento quimioterápico, não houve aumento de risco estatisticamente significativo. As análises das curvas de sobrevida realizadas por Widschwendter et al. ${ }^{20}$ evidenciaram diferenças estatisticamente significativas tanto para SLD quanto para SG. Os outros três estudos não apresentaram resultados com significância estatística ${ }^{19,33,34}$ (Tabela 3).

Embora grandes avanços tenham sido alcançados tanto no diagnóstico quanto na terapêutica do câncer de mama, incorporando tratamentos mais eficazes, incluindo terapia-alvo com bloqueio de $\mathrm{RH}$ e/ou de HER2, estes são destinados a casos de tumores RH positivo e/ou HER2 superexpresso e náo aos $\mathrm{TN}^{63,64}$. Esse subtipo corresponde a 15\% a 20\% dos casos de câncer de mama $^{58,59} \mathrm{e}$ é identificado pela ausência de expressão para RE e RP e ausência de superexpressáo de HER2, o que limita as opçôes terapêuticas disponíveis. É caracterizado por ocorrer em mulheres jovens e está associado a um curso biologicamente agressivo, com maior chance de recorrência precoce, durante os três a cinco primeiros anos após o diagnóstico ${ }^{65}$, conduzindo a um pior prognóstico quando comparado a outros subtipos tumorais ${ }^{63-65}$. Assim, esforços têm sido direcionados para identificar outros fatores prognósticos, modificáveis ou não, que possam ser utilizados para estratificar as mulheres em categorias de risco $^{36}$; entre esses fatores, está a obesidade, considerada um fator de risco modificável, que tem sido associada tanto ao aumento do risco de câncer de mama, incluindo o $\mathrm{TN}^{66}$, quanto à recidiva da doença e à mortalidade ${ }^{4,36}$. Dos 17 estudos que analisaram a interferência do IMC na sobrevida de mulheres com o subtipo TN, 16 realizaram análise de risco ${ }^{14,19-21,24-27,30-32,34-38}$. Em três deles, foi observado aumento no risco de recorrência da doença para mulheres na maior categoria de $\mathrm{IMC}^{20,34,37}$; no estudo de Bonsang-Kitzis et al. ${ }^{37}$, o aumento no risco de 
recorrência foi observado tanto para o grupo de mulheres sem comprometimento linfonodal quanto para aquelas com comprometimento linfonodal e grau III, na pré e na pós-menopausa; dois mostraram aumento no risco para mortalidade global para mulheres na maior categoria de IMC ${ }^{20,31}$. Vale notar que, no estudo de Hao et al. ${ }^{31}$, quando a análise foi estratificada por status menopausal, houve aumento de risco apenas para mulheres na pré-menopausa, grupo que também apresentou aumento no risco de mortalidade por câncer de mama ${ }^{31}$. Oito estudos analisaram as curvas de sobrevida; em dois deles, foi observada diferença estatisticamente significativa nas curvas de $\mathrm{SLD}^{34}$; em dois, houve diferença na curva de $S G^{20,31}$; e, em apenas um, foi observada diferença nas curvas de SRC ${ }^{31}$. De forma global, em 13 dos 17 estudos que realizaram análise de risco, não foi observada associação entre o IMC e recidiva ou morte por câncer de mama TN $^{14,19,21,24-27,29,30,32,35,36,38}$; e, em cinco dos oito estudos que realizaram análise das curvas de sobrevida, não houve diferença estatisticamente significativa, sugerindo que o IMC pode não ser um fator prognóstico negativo para mulheres com esse subtipo tumoral (Tabela 4).

A obesidade é associada com um aumento de $88 \%$ na taxa de mortalidade por câncer em mulheres ${ }^{67}$. O papel do tecido adiposo, em especial os adipócitos, na iniciação e progressão tumoral, é uma área de investigação relativamente nova. Alguns mecanismos têm sido propostos para elucidar a relaçáo entre a obesidade e o câncer de mama; entre eles, a elevação nos níveis de insulina e/ou fator de crescimento semelhante à insulina (IGF) e a desregulação nos níveis de algumas adipocitocinas, além da alteração nos hormônios sexuais ${ }^{68}$. $\mathrm{Na}$ obesidade, ocorre intensa lipólise basal, com elevação nos níveis plasmáticos de ácidos graxos livres (AGL) e o armazenamento destes no interior de células não adiposas, levando à lipotoxicidade, com alteração na função de sinalização insulínica e consequente resistência à insulina, ocasionando hiperglicemia e hiperinsulinemia. A insulina estimula a síntese de DNA e, em altas concentraçóes, está relacionada à incidência, à recorrência e à mortalidade por câncer de mama. Paralelamente, a insulina contribui para a síntese e atividade do fator de crescimento relacionado à insulina IGF-1, também envolvido na gênese e progressão do câncer. O grau de adiposidade corporal está relacionado à concentraçáo sanguínea de IGF-1, relacionado ao câncer de mama e que age estimulando a proliferação celular e inibindo a apoptose, além de exercer efeito sinérgico a outros fatores mitogênicos ${ }^{68-70}$. Alguns produtos secretados pelo tecido adiposo, chamados de adipocinas, em especial a leptina, o fator de necrose tumoral alfa (TNF- $\alpha$ ) e a interleucina-6 (IL-6), têm sido associados ao câncer. A leptina tem sido caracterizada como um fator de crescimento para células neoplásicas, estimulando crescimento celular, migração, invasão e angiogênese tumoral $^{71}$. Um estudo com imuno-histoquímica verificou que receptores de leptina náo foram encontrados em células epiteliais mamárias normais; enquanto, em células de carcinoma mamário, houve coloração positiva em $83 \%$ dos casos ${ }^{72}$. Tem sido observado que o elevado nível plasmático de leptina aumenta o risco para câncer de mama em mulheres na pós-menopausa; enquanto, naquelas na pré-menopausa, é encontrada associação inversa ${ }^{73}$, mostrando que o status menopausal pode influenciar o efeito da leptina sobre a carcinogênese mamária. A leptina induz à transcrição da enzima aromatase, aumentando a produção de estradiol, hormônio promotor do câncer de mama ${ }^{68,71}$, podendo o efeito desse aumento no nível sanguíneo ser diferenciado, a depender do status menopausal. Tem sido sugerido que a leptina é capaz de induzir à proliferação de células neoplásicas mamárias por aumentar a expressão de enzimas proteolíticas que são essenciais no processo de metastatização e na estimulaçáo da angiogênese necessária ao crescimento tumoral ${ }^{71}$, provavelmente por intermédio do aumento da expressão da enzima ciclo-oxigenase-2 (COX-2) endotelial e do fator de crescimento endotelial vascular (FCEV) ${ }^{74}$. O TNF- $\alpha$ está relacionado à gênese tumoral mamária especialmente por exacerbar a resistência à insulina pela redução da expressão do transportador de glicose de superfície celular (GLUT-4) e pela fosforilação específica do receptor de insulina. Além disso, induz à lipólise, contribuindo para a lipotoxicidade e efeitos correlacionados ${ }^{68,75}$. A IL-6, uma citocina imunomoduladora produzida no tecido adiposo, preferencialmente naquele localizado na regiáo visceral, tem seus níveis aumentados na obesidade. Apresenta ação endócrina e pró-inflamatória ${ }^{76}$, estimula a expressão de aromatase no tecido adiposo, ocasionando a biossíntese de estrogênio, e age como um fator antiapoptótico por inibir a ativação de proteases envolvidas na apoptose, além de promover a migraçáo celular. Dessa forma, a IL-6 pode, possivelmente, contribuir diretamente para a gênese e a progressão do câncer de mama ${ }^{68}$.

Os mecanismos relacionados à alteração nos hormônios sexuais envolvem tanto a síntese quanto a bioatividade dos estrógenos. A biossíntese de estrogênio difere em mulheres na pré e pós-menopausa. Na pós-menopausa, o tecido adiposo assume uma importante influência nos níveis de estrógenos circulantes, aumentando o tempo de exposição das células mamárias a esses hormônios ${ }^{77}$. Adicionalmente, a célula adiposa influencia a síntese e a bioatividade dos hormônios esteroides sexuais por intermédio de, pelo menos, dois mecanismos. O primeiro relacionado à síntese de estrogênio, em que o tecido adiposo executa atividade esteroidogênica por intermédio de duas vias bioquímicas 
Pinheiro RL, Monteiro GTR

Tabela 4. Efeito do índice de massa corporal na sobrevida de mulheres com câncer de mama triplo-negativo

\begin{tabular}{|c|c|c|c|c|c|c|c|c|c|c|}
\hline \multirow{3}{*}{$\begin{array}{l}\text { Primeiro autor/ } \\
\text { ano/país }\end{array}$} & \multirow{3}{*}{ Pontos de corte para IMC } & \multicolumn{6}{|c|}{ Hazard ratio } & \multirow{2}{*}{\multicolumn{3}{|c|}{$\begin{array}{l}\text { Kaplan-Meier } \\
\text { Log-rank test }\end{array}$}} \\
\hline & & \multicolumn{2}{|c|}{ SLD } & \multicolumn{2}{|c|}{ SG } & \multicolumn{2}{|c|}{ SRC } & & & \\
\hline & & HR & IC $95 \%$ & HR & IC $95 \%$ & HR & IC $95 \%$ & SLD & SG & SRC \\
\hline $\begin{array}{l}\text { Ademuyiwa et al. } \\
(2011)^{a} 24 \\
\text { EUA }\end{array}$ & $\begin{array}{l}<25,0 \mathrm{~kg} / \mathrm{m}^{2} \\
25,0-29,9 \mathrm{~kg} / \mathrm{m}^{2} \\
\geq 30,0 \mathrm{~kg} / \mathrm{m}^{2}\end{array}$ & $\begin{array}{l}1,00 \\
0,74 \\
0,81\end{array}$ & $\begin{array}{l}0,43-1,27 \\
0,49-1,34\end{array}$ & $\begin{array}{l}1,00 \\
0,60 \\
0,94\end{array}$ & $\begin{array}{l}0,32-1,14 \\
0,54-1,64\end{array}$ & - & - & $p=0,93 \S$ & $p=0,57^{\S}$ & \\
\hline $\begin{array}{l}\text { Dawood et al. } \\
(2012)^{36} \\
\text { EUA }\end{array}$ & $\begin{array}{l}<25,0 \mathrm{~kg} / \mathrm{m}^{2} \\
25,0-29,9 \mathrm{~kg} / \mathrm{m}^{2} \\
\geq 30,0 \mathrm{~kg} / \mathrm{m}^{2}\end{array}$ & $\begin{array}{l}1,00 \\
1,09 \\
1,02\end{array}$ & $\begin{array}{l}0,92-1,29 \\
0,86-1,20\end{array}$ & $\begin{array}{l}1,00 \\
1,00 \\
0,97\end{array}$ & $\begin{array}{c}0,83-1,2 \\
0,81-1,16\end{array}$ & - & - & $p=0,54^{\S}$ & $p=0,93^{\S}$ & \\
\hline $\begin{array}{l}\text { Sparano et al. } \\
(2012)^{114} \\
\text { EUA }\end{array}$ & $\begin{array}{l}<30,0 \mathrm{~kg} / \mathrm{m}^{2} \\
\geq 30,0 \mathrm{~kg} / \mathrm{m}^{2}\end{array}$ & $\begin{array}{l}1,00 \\
1,02\end{array}$ & $0,80-1,30$ & $\begin{array}{l}1,00 \\
1,11\end{array}$ & $0,85-1,46$ & $\begin{array}{l}1,00 \\
1,00\end{array}$ & $0,74-1,36$ & & & \\
\hline $\begin{array}{l}\text { Mowad et al. } \\
(2013)^{\mathrm{d} 25} \\
\text { EUA }\end{array}$ & $\begin{array}{l}<25,0 \mathrm{~kg} / \mathrm{m}^{2} \\
\geq 30,0 \mathrm{~kg} / \mathrm{m}^{2} \\
<25,0 \mathrm{~kg} / \mathrm{m}^{2} \\
25,0-29,9 \mathrm{~kg} / \mathrm{m}^{2} \\
\geq 30,0 \mathrm{~kg} / \mathrm{m}^{2}\end{array}$ & $\begin{array}{c}1,00 \\
1,01 \\
-\end{array}$ & $\begin{array}{c}0,67-1,52 \\
-\end{array}$ & $\begin{array}{c}1,00 \\
1,36 \\
-\end{array}$ & $\begin{array}{c}0,77-2,42 \\
-\end{array}$ & - & - & $\mathrm{p}=0,91^{\S}$ & $-p=0,29 \S$ & \\
\hline $\begin{array}{l}\text { Pajares et al. } \\
(2013)^{\mathrm{e}} 19 \\
\text { Espanha }\end{array}$ & $\begin{array}{l}<25,0 \mathrm{~kg} / \mathrm{m}^{2} \\
\geq 35,0 \mathrm{~kg} / \mathrm{m}^{2}\end{array}$ & $\begin{array}{c}1,00 \\
1,4\end{array}$ & $0,9-2,3$ & $\begin{array}{c}1,00 \\
1,4\end{array}$ & $0,9-2,2$ & $\begin{array}{c}1,00 \\
1,3\end{array}$ & $0,8-2,3$ & - & - & - \\
\hline $\begin{array}{l}\text { Turkoz et al. } \\
(2013)^{f 26} \\
\text { Turquia }\end{array}$ & $\begin{array}{l}18,5-24,9 \mathrm{~kg} / \mathrm{m}^{2} \\
\geq 30,0 \mathrm{~kg} / \mathrm{m}^{2}\end{array}$ & - & - & $\begin{array}{c}1,00 \\
1,4\end{array}$ & $1,0-2,1$ & - & - & - & - & - \\
\hline $\begin{array}{l}\text { Tait et al. } \\
(2014)^{g 27} \\
\text { EUA }\end{array}$ & $\begin{array}{l}\text { Global } \\
<25,0 \mathrm{~kg} / \mathrm{m}^{2} \\
25,0-29,9 \mathrm{~kg} / \mathrm{m}^{2} \\
30,0-34,9 \mathrm{~kg} / \mathrm{m}^{2} \\
\geq 35,0 \mathrm{~kg} / \mathrm{m}^{2} \\
\text { Pós-menopausa vs pré- } \\
\text {-menopausa } \\
<25,0 \mathrm{~kg} / \mathrm{m}^{2} \\
25,0-29,9 \mathrm{~kg} / \mathrm{m}^{2} \\
30,0-34,9 \mathrm{~kg} / \mathrm{m}^{2} \\
\geq 35,0 \mathrm{~kg} / \mathrm{m}^{2}\end{array}$ & $\begin{array}{l}1,00 \\
1,01 \\
0,94 \\
0,99\end{array}$ & $\begin{array}{l}0,65-1,56 \\
0,60-1,47 \\
0,63-1,57 \\
\\
0,49-1,82 \\
0,29-1,01 \\
0,53-1,91 \\
0,38-1,56\end{array}$ & $\begin{array}{l}1,00 \\
1,22 \\
0,92 \\
1,16\end{array}$ & $\begin{array}{l}0,78-1,91 \\
0,59-1,43 \\
0,70-1,90 \\
\\
0,50-1,89 \\
0,45-1,74 \\
0,63-2,52 \\
0,33-1,50\end{array}$ & - & - & $\mathrm{p}=0,84 \S$ & $p=0,82 \S$ & - \\
\hline $\begin{array}{l}\text { Bonsang-Kitzis et } \\
\text { al. }(2015)^{\mathrm{h} 37} \\
\text { França }\end{array}$ & $\begin{array}{l}\leq 30,0 \mathrm{~kg} / \mathrm{m}^{2} \\
>30,0 \mathrm{~kg} / \mathrm{m}^{2} \\
\mathrm{pN}- \\
\leq 30,0 \mathrm{~kg} / \mathrm{m}^{2} \\
>30,0 \mathrm{~kg} / \mathrm{m}^{2} \\
\\
\mathrm{pN}+\text { grau I-II } \\
\leq 30,0 \mathrm{~kg} / \mathrm{m}^{2} \\
>30,0 \mathrm{~kg} / \mathrm{m}^{2} \\
\mathrm{pN}+\text { grau III pré-menopausa } \\
\leq 30,0 \mathrm{~kg} / \mathrm{m}^{2} \\
>30,0 \mathrm{~kg} / \mathrm{m}^{2} \\
\mathrm{pN}+\mathrm{grau} \mathrm{III} \mathrm{pós-menopausa} \\
\leq 30,0 \mathrm{~kg} / \mathrm{m}^{2} \\
>30,0 \mathrm{~kg} / \mathrm{m}^{2}\end{array}$ & $\begin{array}{l}1,00 \\
1,71 \\
1,00 \\
2,64 \\
1,00 \\
1,29 \\
1,00 \\
9,68 \\
\\
1,00 \\
3,57\end{array}$ & $\begin{array}{l}0,81-2,83 \\
1,28-5,55 \\
0,39-4,26 \\
5,71-18,31 \\
1,69-7,77\end{array}$ & - & - & - & - & - & - & - \\
\hline $\begin{array}{l}\text { Cakar et al. } \\
(2015)^{i 29} \\
\text { Turquia }\end{array}$ & $\begin{array}{l}<25,0 \mathrm{~kg} / \mathrm{m}^{2} \\
25,0-29,9 \mathrm{~kg} / \mathrm{m}^{2} \\
\geq 30,0 \mathrm{~kg} / \mathrm{m}^{2}\end{array}$ & - & - & - & - & & & $\begin{array}{l}p=0,16 \# \\
p=0,49 \#\end{array}$ & $\begin{array}{c}\mathrm{p}=0,30 \# \\
\text { SA }\end{array}$ & \\
\hline $\begin{array}{l}\text { Fan et al. } \\
(2015)^{i 30} \\
\text { China }\end{array}$ & $\begin{array}{l}<25,0 \mathrm{~kg} / \mathrm{m}^{2} \\
\geq 25,0 \mathrm{~kg} / \mathrm{m}^{2}\end{array}$ & $\begin{array}{l}1,00 \\
1,28\end{array}$ & $0,81-2,02$ & $\begin{array}{l}1,00 \\
1,13\end{array}$ & $0,62-2,05$ & - & - & - & - & - \\
\hline
\end{tabular}


Tabela 4. continuação

\begin{tabular}{|c|c|c|c|c|c|c|c|c|c|c|}
\hline \multirow{3}{*}{$\begin{array}{l}\text { Primeiro autor/ } \\
\text { ano/país }\end{array}$} & \multirow{3}{*}{ Pontos de corte para IMC } & \multicolumn{6}{|c|}{ Hazard ratio } & \multirow{2}{*}{\multicolumn{3}{|c|}{$\begin{array}{l}\text { Kaplan-Meier } \\
\text { Log-rank test }\end{array}$}} \\
\hline & & \multicolumn{2}{|c|}{ SLD } & \multicolumn{2}{|c|}{ SG } & \multicolumn{2}{|c|}{ SRC } & & & \\
\hline & & HR & IC $95 \%$ & HR & IC $95 \%$ & HR & IC $95 \%$ & SLD & SG & SRC \\
\hline $\begin{array}{l}\text { Hao et al. } \\
(2015)^{\mathrm{k} 31} \\
\text { China }\end{array}$ & $\begin{array}{l}\text { Todos os pacientes } \\
\leq 24,0 \mathrm{~kg} / \mathrm{m}^{2} \\
>24,0 \mathrm{~kg} / \mathrm{m}^{2} \\
\text { Pré-menopausa } \\
\leq 24,0 \mathrm{~kg} / \mathrm{m}^{2} \\
>24,0 \mathrm{~kg} / \mathrm{m}^{2} \\
\\
\text { Pós-menopausa } \\
\leq 24,0 \mathrm{~kg} / \mathrm{m}^{2} \\
>24,0 \mathrm{~kg} / \mathrm{mv}\end{array}$ & - & - & $\begin{array}{l}1,00 \\
1,46 \\
1,00 \\
2,16 \\
1,00 \\
1,07\end{array}$ & 1,04-2,06 & $\begin{array}{l}1,00 \\
1,34 \\
1,00 \\
2,27 \\
\\
1,00 \\
0,96\end{array}$ & $\begin{array}{l}1,11-4,63 \\
0,58-1,58\end{array}$ & - & $\begin{array}{l}p=0,01^{*} \\
p=0,01 v \\
p=0,35^{*}\end{array}$ & $\begin{array}{l}p=0,01^{*} \\
p=0,00^{*} \\
p=0,57^{*}\end{array}$ \\
\hline $\begin{array}{l}\text { Jeon et al. } \\
(2015)^{132} \\
\text { Coreia }\end{array}$ & $\begin{array}{l}<18,5 \mathrm{~kg} / \mathrm{mv} \\
18,5-24,9 \mathrm{~kg} / \mathrm{mv} \\
25,0-29,9 \mathrm{~kg} / \mathrm{mv} \\
\geq 30,0 \mathrm{~kg} / \mathrm{m}^{2}\end{array}$ & - & - & $\begin{array}{l}1,19 \\
1,00 \\
1,07 \\
1,18\end{array}$ & $\begin{array}{l}0,84-1,68 \\
0,93-1,23 \\
0,90-1,55\end{array}$ & $\begin{array}{l}1,27 \\
1,00 \\
0,93 \\
1,16\end{array}$ & $\begin{array}{l}0,84-1,92 \\
0,79-1,11 \\
0,84-1,61\end{array}$ & - & - & - \\
\hline $\begin{array}{l}\text { Ligibel et al. } \\
(2015)^{\mathrm{m} 35} \\
\text { EUA }\end{array}$ & $\begin{array}{l}\text { Para cada } 5 \text { unidades de } \\
\text { aumento de IMC }\end{array}$ & 1,11 & $0,97-1,28$ & - & - & - & - & - & - & - \\
\hline $\begin{array}{l}\text { Widschwendter et } \\
\text { al. }(2015)^{\mathrm{n} 20} \\
\text { Alemanha }\end{array}$ & $\begin{array}{l}<25,0 \mathrm{~kg} / \mathrm{m}^{2} \\
25,0-29,9 \mathrm{~kg} / \mathrm{m}^{2} \\
30,0-34,9 \mathrm{~kg} / \mathrm{m}^{2} \\
35,0-39,9 \mathrm{~kg} / \mathrm{m}^{2} \\
\geq 30,0 \mathrm{~kg} / \mathrm{m}^{2}\end{array}$ & $\begin{array}{l}1,00 \\
1,34 \\
1,29 \\
0,36 \\
3,02\end{array}$ & $\begin{array}{l}0,91-1,97 \\
0,77-2,17 \\
0,09-1,48 \\
1,50-6,08\end{array}$ & $\begin{array}{l}1,00 \\
1,41 \\
1,27 \\
0,51 \\
3,85\end{array}$ & $\begin{array}{l}0,88-2,25 \\
0,67-2,41 \\
0,12-2,21 \\
1,69-8,77\end{array}$ & - & - & $\mathrm{p}<0,01^{*}$ & $\mathrm{p}<0,01^{*}$ & \\
\hline $\begin{array}{l}\text { Bao et al. } \\
(2016)^{021} \\
\text { China }\end{array}$ & $\begin{array}{l}<18,5 \mathrm{~kg} / \mathrm{m}^{2} \\
18,5-23,9 \mathrm{~kg} / \mathrm{m}^{2} \\
24,0-27,9 \mathrm{~kg} / \mathrm{m}^{2} \\
\geq 28,0 \mathrm{~kg} / \mathrm{m}^{2}\end{array}$ & $\begin{array}{l}1,28 \\
1,00 \\
1,38 \\
1,53\end{array}$ & $\begin{array}{l}0,57-2,89 \\
0,88-2,17 \\
0,84-2,77\end{array}$ & $\begin{array}{l}1,16 \\
1,00 \\
1,19 \\
1,36\end{array}$ & $\begin{array}{l}0,54-2,50 \\
0,79-1,81 \\
0,78-2,40\end{array}$ & - & - & - & - & - \\
\hline $\begin{array}{l}\text { Kawai et al. } \\
(2016)^{\text {p38 }} \\
\text { Japão }\end{array}$ & $\begin{array}{l}<18,5 \mathrm{~kg} / \mathrm{m}^{2} \\
18,5-21,7 \mathrm{~kg} / \mathrm{m}^{2} \\
21,8-24,0 \mathrm{~kg} / \mathrm{m}^{2} \\
25,0-30,0 \mathrm{~kg} / \mathrm{m}^{2} \\
\geq 30,0 \mathrm{~kg} / \mathrm{m}^{2}\end{array}$ & $\begin{array}{l}1,15 \\
1,00 \\
1,08 \\
0,95 \\
1,09\end{array}$ & $\begin{array}{l}0,84-1,57 \\
0,89-1,31 \\
0,75-1,20 \\
0,74-1,62\end{array}$ & - & - & $\begin{array}{l}0,97 \\
1,00 \\
1,15 \\
1,03 \\
1,11\end{array}$ & $\begin{array}{l}0,62-1,51 \\
0,90-1,48 \\
0,77-1,39 \\
0,67-1,84\end{array}$ & - & - & - \\
\hline $\begin{array}{l}\text { Liu ef al. } \\
(2018)^{q 34} \\
\text { EUA }\end{array}$ & $\begin{array}{l}<30,0 \mathrm{~kg} / \mathrm{m}^{2} \\
\geq 30,0 \mathrm{~kg} / \mathrm{m}^{2}\end{array}$ & $\begin{array}{c}1 \\
2,62\end{array}$ & $1,03-6,66$ & $\begin{array}{c}1 \\
3,00\end{array}$ & $0,95-9,51$ & - & - & $p=0,04^{£}$ & $p=0,06^{£}$ & - \\
\hline
\end{tabular}

Legendas: IMC = índice de massa corporal; SLD = sobrevida livre de doença; SG = sobrevida global; SRC = sobrevida relacionada ao câncer; HR = Hazard ratio; $\mathrm{IC}$ = intervalo de confiança; $\mathrm{pN}$ = comprometimento de linfonodos no exame histopatológico; $\mathrm{SA}=$ sem análise

${ }^{a}$ Ajustado para idade, raça, ano do diagnóstico, tipo histológico, estadiamento, grau tumoral, presença de invasão vascular e quimioterapia.

${ }^{\mathrm{b}}$ Ajustado para idade, raça, estadiamento, invasão linfática e vascular, tratamentos adjuvante sistêmico e radioterapia.

'Ajustado para idade, raça, status menopausal, tamanho tumoral, n. ${ }^{\circ}$ de nódulo linfático axilar positivo, tipo de cirurgia, radioterapia, quimioterapia e hormonioterapia (dependendo do braço de tratamento do ensaio clínico).

$\mathrm{d}, \mathrm{h}, \mathrm{j}$ Variáveis de ajuste năo informadas.

' Ajustado para idade, status menopausal, tamanho tumoral, status nodal, grau histológico, status de RH, status de HER2, tipo de cirurgia, subtratamento global, estudo (incluindo status nodal).

${ }^{\mathrm{f}}$ Ajustado para idade, tamanho tumoral, envolvimento nodal, grau histológico, invasão linfovascular e perineural, extensão extracapsular, status hormonal.

g Ajustado para estadiamento patológico.

${ }^{i}$ Ajustado para status menopausal.

${ }^{\mathrm{k}}$ Ajustado para idade, status menopausal, tamanho tumoral, status nodal, grau e terapia adjuvante sistêmica.

' Ajustado para idade, tamanho tumoral, status nodal, grau histológico, método cirúrgico, tratamento adjuvante, status de RE e RP e expressão de HER2.

m, q Não ajustado.

${ }^{\mathrm{n}}$ Ajustado para idade, tamanho tumoral, status nodal, grau tumoral, tipo histológico, status de receptor hormonal, status de HER2, status menopausal, tipo de cirurgia, tratamento quimioterápico, terapia hormonal e subtratamento quimioterápico.

- Ajustado para idade, nível educacional, status menopausal, index de comorbidade Charlson, participaçáo em exercício, estadiamento TNM, tipo de cirurgia, quimioterapia e radioterapia.

P Ajustado para idade, regiâo de residência, método de detecçáo, história familiar do câncer de mama, estágio tumoral, radioterapia, quimioterapia, terapia endócrina, status menopausal e ano de registro.

$\$$ Tempo de sobrevida em 5 anos.

${ }^{¥}$ Tempo de sobrevida náo informado.

${ }^{E}$ Tempo de sobrevida em 3 anos. 
relacionadas às enzimas $17-\beta$ hidroxiesteroide oxiredutase e aromatase $\mathrm{P} 450$, que participam da conversão de precursores androgênicos em estrogênio, contribuindo significativamente para a elevação nos níveis sanguíneos de esteroides sexuais na pós-menopausa ${ }^{76,78}$. Em mulheres na pós-menopausa, o aumento do IMC está associado a um incremento significativo nos níveis plasmáticos de estrona e estradiol ${ }^{79}$. O segundo mecanismo diz respeito à bioatividade do estrogênio. $\mathrm{O}$ excesso de adiposidade corporal resulta em um aumento no nível sanguíneo de insulina e na bioatividade do IGF-1, ambos capazes de inibir a síntese da globulina carreadora de hormônios sexuais (SHBG), resultando em maior disponibilidade de estrogênio livre para agir na célula-alvo. $\mathrm{O}$ estudo realizado por McTiernan et al. ${ }^{80}$ mostrou que mulheres com IMC $>30 \mathrm{~kg} / \mathrm{m}^{2}$ apresentaram concentração média de SHBG $50 \%$ menor do que aquelas com IMC $<22 \mathrm{~kg} / \mathrm{m}^{2}$. O estrogênio induz à mitose nas células epiteliais mamárias e inibe a apoptose; assim, a exposição ao estrogênio e/ou ao aumento na expressáo de receptores de estrogênio nas células epiteliais mamárias aumentam o risco tanto para o desenvolvimento quanto para a progressão do câncer de mama ${ }^{68}$.

No que se refere ao status menopausal, três estudos analisaram a pré e a pós-menopausa de formas separadas ${ }^{27,31,36}$; em outros oito, foi considerado como variável de ajuste $14,18-21,29,37,38$; dois estudos incluíram apenas mulheres na pré-menopausa ${ }^{26,39}$; cinco apenas informaram o quantitativo de pré e pós-menopausa ${ }^{22,28,33,35,36}$; e seis não apresentaram informaçôes ${ }^{23-25,30,32,34}$ (Tabela 1). Considerando os mecanismos que relacionam a obesidade ao risco e à progressão do câncer de mama, o status menopausal é importante fator na determinação da influência da obesidade sobre a doença, via mecanismos relacionados à leptina e à alteração nos hormônios sexuais. Assim, é provável que o excesso de adiposidade corporal exerça influência diferenciada em mulheres na pré e na pós-menopausa. Destarte, essa variável deve ser considerada nas análises de estudos que buscam verificar a influência da obesidade sobre a sobrevida em mulheres com câncer de mama.

Um fato importante observado nesta revisão foi a diferença encontrada nas definiçóes de sobrevida entre os estudos. Classicamente, a SG é definida como o período de tempo durante o qual um paciente permanece vivo após o diagnóstico da doença ou início do tratamento; SLD, como o período em que não são detectados sinais nem sintomas da doença após um tratamento curativo, sendo o desfecho identificado quando ocorre a recorrência da doença (local ou a distância) ou morte por qualquer causa; e SRC, o tempo entre o diagnóstico e a morte pela doença ${ }^{81,82}$. Apenas quatro, entre os 23 estudos incluídos nesta revisão, adotaram as definiçóes clássicas para sobrevida ${ }^{27,28,32,37}$, configurando diferenças metodológicas que impedem a comparação dos resultados obtidos e mostrando a necessidade da uniformizaçáo dos termos.

Esta revisão foi planejada e executada de acordo com protocolos específicos e diretrizes estabelecidas, tendo seguido todas as etapas previstas para realização de uma revisão integrativa de literatura, o que assegura o rigor metodológico do estudo. Como o objetivo foi o de realizar síntese e análise narrativa do conhecimento produzido sobre o tema, optou-se por não limitar a seleção dos estudos em razão das diferenças metodológicas, mas sim, descrevê-las e discuti-las. Para localizaçáo dos estudos, foram utilizadas quatro das principais bases de dados; entretanto, algumas bases não foram incluídas na estratégia de busca por conta da restrição de acesso, considerada uma limitação do estudo, assim como da restrição quanto ao idioma de publicação.

\section{CONCLUSÃO}

Com base nos resultados dos estudos incluídos nesta revisão, o efeito do excesso de peso, em especial a obesidade, no prognóstico de mulheres com câncer de mama, pode ser diferenciado de acordo com o subtipo tumoral, sendo que a obesidade parece exercer maior influência na sobrevida de mulheres com tumores luminais, do que naquelas com subtipos HER2 superexpresso ou TN. Entretanto, no presente momento, os dados ainda são inconsistentes, não havendo corpo de evidência suficiente para responder a essa questão. As diferenças metodológicas observadas nas definiçôes de sobrevida, nos tempos de seguimento, nas variáveis de ajustes, em especial no que se refere ao status menopausal, na forma e no momento de obtençáo das variáveis peso e altura para estimativa do IMC e na classificação dos subtipos tumorais, em particular para os tumores luminais, dificultam a comparação entre os resultados publicados. Mais estudos, com rigor metodológico adequado aos objetos de investigaçẫo, são necessários para formar um corpo de conhecimento sólido, que poderá não só responder à questão de pesquisa, mas também nortear programas de intervenção nutricional específicos, direcionados às mulheres com câncer de mama.

\section{CONTRIBUIÇÕES}

Rosilene de Lima Pinheiro e Gina Torres Rego Monteiro contribuíram substancialmente na concepção e no planejamento do estudo; na obtenção, análise e interpretaçáo dos dados; assim como na redação, revisão crítica e aprovação final da versão publicada. 


\section{DECLARAÇÃO DE CONFLITO DE INTERESSES}

Nada a declarar.

\section{FONTES DE FINANCIAMENTO}

Não há.

\section{REFERÊNCIAS}

1. Eichholzer M, Huang DJ, Modlasiak A, et al. Impact of body mass index on prognostically relevant breast cancer tumor characteristics. Breast Care (Basel). 2013;8(3):1928. doi: https://doi.org/10.1159/000350002.

2. Sueta A, Ito H, Islam T, et al. Differential impact of body mass index and its change on the risk of breast cancer by molecular subtype: a case-control study in Japanese women. Springerplus. 2012;1(1):39. doi: https://doi. org/10.1186/2193-1801-1-39.

3. Sun L, Zhu Y, Qian Q, Tang L. Body mass index and prognosis of breast câncer: an analysis by menstruation status when breast cancer diagnosis. Medicine (Baltimore). 2018;97(26):e11220. doi: https://doi.org/10.1097/ MD.0000000000011220.

4. Ayoub NM, Yaghan RJ, Abdo NM, et al. Impact of obesity on clinicopathologic characteristics and disease prognosis in pre- and postmenopausal breast cancer patients: a retrospective institutional study. J Obes. 2019;ID 3820759. doi: https://doi.org/10.1155/2019/3820759.

5. Protani M, Coory M, Martin JH. Effect of obesity on survival of women with breast cancer: systematic review and meta-analysis. Breast Cancer Res Treat. 2010;123(3):627-35. doi: https://doi.org/10.1007/ s10549-010-0990-0.

6. Azrad M, Demark-Wahnefried W. The association between adiposity and breast cancer recurrence and survival: a review of the recent literature. Curr Nutr Rep. 2014;3(1):9-15. doi: https://doi.org/10.1007/s13668013-0068-9.

7. Hauner D, Janni W, Rack B, et al. The effect of overweight and nutrition on prognosis in breast cancer. Dtsch Arztebl Int. 2011;108(47):795-801. doi: https:// doi.org/10.3238 / arztebl.2011.0795.

8. Karatas F, Erdem GU, Sahin S, et al. Obesity is an independent prognostic factor of decreased pathological complete response to neoadjuvant chemotherapy in breast cancer patients. Breast. 2017; 32:237-44. doi: https://doi.org/10.1016/j.breast.2016.05.013.

9. Widschwendter P, Friedl TW, Schwentner L, et al. The influence of obesity on survival in early, high-risk breast cancer: results from the randomized SUCCESS A trial. Breast Cancer Res. 2015;17:129. doi: https://doi. org/10.1186/s13058-015-0639-3.
10. Elwood JM, Tin Tin S, Kuper-Hommel M, et al. Obesity and breast cancer outcomes in chemotherapy patients in New Zealand - a population-based cohort study. BMC Cancer. 2018;18(1):76. doi: https://doi.org/10.1186/ s12885-017-3971-4.

11. Warren LE, Ligibel JA, Chen YH, et al. Body Mass Index and locoregional recurrence in women with earlystage breast cancer. Ann Surg Oncol. 2016;23(12):387079. doi: https://doi.org/10.1245/s10434-016-5437-3.

12. Gennari A, Amadori D, Scarpi E, et al. Impact of body mass index (BMI) on the prognosis of highrisk early breast cancer (EBC) patients treated with adjuvant chemotherapy. Breast Cancer Res Treat. 2016 Aug;159(1):79-86. doi: https://doi.org/10.1007/s10549016-3923-8.

13. Ewertz M, Gray KP, Regan MM, et al. Obesity and risk of recurrence or death after adjuvant endocrine therapy with letrozole or tamoxifen in the breast international group 1-98 trial. J Clin Oncol. 2012;30(32):3967-75. doi: https://doi.org/10.1200/JCO.2011.40.8666.

14. Sparano JA, Wang M, Zhao F, et al. Obesity at diagnosis is associated with inferior outcomes in hormone receptor-positive operable breast cancer. Cancer. 2012;118(23):5937-46. doi: https://doi.org/10.1002/ cncr.27527.

15. Botelho LLR, Cunha CCA, Macedo M. O método de revisão integrativa nos estudos organizacionais. Gestão e Sociedade. 2011; 5(11):121-36. doi: https://doi. org/10.21171/ges.v5i11.1220.

16. Whittemore R, Knafl K. The integrative review: updated methodology. J Adv Nurs. 2005;52(5):546-53. doi: https://doi.org/10.1111/j.1365-2648.2005.03621.x.

17. Ministério da Saúde (BR), Secretaria de Ciência, Tecnologia e Insumos Estratégicos, Departamento de Ciência e Tecnologia. Diretrizes metodológicas: elaboração de revisão sistemática e metanálise de estudos observacionais comparativos sobre fatores de risco e prognóstico. Brasília: Ministério da Saúde; 2014.

18. Mazzarella L, Disalvatone D, Bagnardi V, et al. Obesity increases the incidence of distant metastases in oestrogen receptor-negative human epidermal growth factor receptor 2-positive breast cancer patients. Eur J Cancer. 2013;49(17):3588-97. doi: https://doi.org/10.1016/j. ejca.2013.07.016.

19. Pajares B, Pollán M, Martín M, et al. Obesity and survival in operable breast cancer patients treated with adjuvant anthracyclines and taxanes according to pathological subtypes: a pooled analysis. Breast Cancer Res. 2013;15(6):R105. doi: https://doi.org/10.1186/ bcr3572.

20. Widschwendter P, Friedl TW, Schwentner L, DeGregorio $\mathrm{N}$, Jaeger B, Schramm A, et al. The influence of obesity on survival in early, high-risk breast cancer: results from the randomized SUCCESS A trial. Breast Cancer Res. 
2015;17:129. doi: https://doi.org/10.1186/s13058015-0639-3.

21. Bao PP, Cai H, Peng P, et al. Body mass index and weight change in relation to triple-negative breast cancer survival. Cancer Causes Control. 2016;27(2):229-36. doi: https://doi.org/10.1007/s10552-015-0700-7

22. Crozier JA, Moreno-Aspitia A, Ballman KV, et al. Effect of body mass index on tumor characteristics and diseasefree survival in patients from the HER2-positive adjuvant trastuzumab trial N9831. Cancer. 2013;119(13):24472454. doi: https://doi.org/10.1002/cncr.28051.

23. Robinson PJ, Bell RJ, Davis SR. Obesity is associated with a poorer prognosis in women with hormone receptor positive breast cancer. Maturitas. 2014;79(3):279-86. doi: https://doi.org/10.1016/j.maturitas.2014.07.004.

24. Ademuyiwa FO, Groman A, O'Connor T, et al. Impact of body mass index on clinical outcomes in triple-negative breast cancer. Cancer. 2011;117(18):4132-40. doi: https://doi.org/10.1002/cncr.26019.

25. Mowad R, Chu QD, Li BD, et al. Does obesity have an effect on outcomes in triple-negative breast cancer?. J Surg Res. 2013;184(1):253-9. doi: https://doi. org/10.1016/j.jss.2013.05.037.

26. Turkoz FP, Solak M, Petekkaya I, et al. The prognostic impact of obesity on molecular subtypes of breast cancer in premenopausal women. J BUON. 2013;18(2):335-41.

27. Tait S, Pacheco JM, Gao F, et al. Body mass index, diabetes, and triple-negative breast cancer prognosis. Breast Cancer Res Treat. 2014;146(1):189-97. doi: https://doi.org/10.1007/s10549-014-3002-y.

28. Xiao Y, Zhang S, Hou G, et al. Clinical pathological characteristics and prognostic analysis of diabetic women with luminal subtype breast cancer. Tumour Biol. 2014;35(3):2035-45. doi: https://doi.org/0.1007/ s13277-013-1270-5.

29. Cakar B, Muslu U, Erdogan AP, et al. The role of body mass index in triple negative breast cancer. Oncol Res Treat. 2015;38(10):518-22. doi: https://doi. org/10.1159/000439551.

30. Fan Y, Ding X, Wang J, et al. Decreased serum HDL at initial diagnosis correlates with worse outcomes for triple-negative breast cancer but not non-TNBCs. Int J Biol Markers. 2015;30(2):e200-7. doi: https://doi. org/10.5301/jbm.5000143.

31. Hao S, Liu Y, Yu KD, et al. Overweight as a prognostic factor for triple-negative breast cancers in Chinese Women. PloS One. 2015; 10(6): e0129741. doi: https:// doi.org/10.1371/journal.pone.0129741.

32. Jeon YW, Kang SH, Park MH, et al. Relationship between body mass index and the expression of hormone receptors or human epidermal growth factor receptor 2 with respect to breast cancer survival. BMC Cancer. 2015;15:865. doi: https://doi.org/110.1186/s12885015-1879-4.
33. Martel S, Poletto E, Ferreira AR, et al. Impact of body mass index on the clinical outcomes of patients with HER2-positive metastatic breast câncer. Breast. 2018;37:142-147. doi: https://doi.org/10.1016/j. breast.2017.11.004.

34. Liu YL, Saraf A, Catanese B, et al. Obesity and survival in the neoadjuvant breast cancer setting: role of tumor subtype in an ethnically diverse population. Breast Cancer Res Treat. 2018;167(1):277-88. doi: https://doi. org/10.1007/s10549-017-4507-y.

35. Ligibel JA, Cirrincione CT, Liu M, et al. Body mass index, PAM50 subtype, and outcomes in node-positive breast cancer: CALGB 9741 (Alliance). J Natl Cancer Inst. 2015;107(9): djv179. doi: https://doi.org/10.1093/ jnci/djv179.

36. Dawood S, Lei X, Litton JK, et al. Impact of body mass index on survival outcome among women with early stage triple-negative breast cancer. Clin Breast Cancer. 2012;12(5):364-72. doi: https://doi.org/10.1016/j. clbc.2012.07.013.

37. Bonsang-Kitzis H, Chaltier L, Belin L, et al. Beyond axillary lymph node metastasis, bmi and menopausal status are prognostic determinants for triple-negative breast cancer treated by neoadjuvant chemotherapy. PloS One. 2015;10(12). doi: https://doi.org/10.1371/ journal.pone.0144359.

38. Kawai M, Tomotaki A, Miyata H, et al. Body mass index and survival after diagnosis of invasive breast cancer: a study based on the Japanese National Clinical DatabaseBreast Cancer Registry. Cancer Med. 2016;5(6):1328-40. doi: https://doi.org/10.1002/cam4.678.

39. Sendur MA, Aksoy S, Ozdemir NY, et al. Effect of body mass index on the efficacy of adjuvant tamoxifen in premenopausal patients with hormone receptor-positive breast cancer. J BUON. 2016;21(1):27-34.

40. World Health Organization. Obesity: preventing and managing the global epidemic: report of a WHO Consultation. Geneva: WHO; 2000. (WHO technical report series; 894).

41. Connor Gorber S, Tremblay M, Moher D, et al. A comparison of direct vs. self-report measures for assessing height, weight and body mass index: a systematic review. Obes Rev. 2007;8(4):307-26. doi: https://doi. org/10.1111/j.1467-789X.2007.00347.x.

42. Engstrom JL, Paterson SA, Doherty A, et al. Accuracy of self-reported height and weight in women: an integrative review of the literature. J Midwifery Womens Health. 2003;48(5):338-45.

43. Martins PC, Carvalho MB, Machado CJ. Uso de Medidas autorreferidas de peso, altura e índice de massa corporal em uma população rural do nordeste brasileiro. Rev Bras Epidemiol. 2015;18(1):137-48. doi: http:// dx.doi.org/10.1590/1980-5497201500010011. 
44. Nawaz H, Chan W, Abdulrahman M, et al. Self-reported weight and height: implications for obesity research. Am J Prev Med. 2001;20(4):294-8.

45. Spencer EA, Appleby PN, Davey GK, et al. Validity of self-reported height and weight in 4808 EPIC-Oxford participants. Public Health Nutr. 2002;5(4):561-5. doi: http://dx.doi.org/10.1079/PHN2001322.

46. Peixoto MRG, Benício MHD, Jardim PCBV. Validade do peso e da altura auto-referidos: o estudo de Goiânia. Rev Saúde Pública. 2006;40(6):1065-72. doi: http://dx.doi. org/10.1590/S0034-89102006000700015.

47. Kuczmarki MF, Kuczmarski RJ, Najar M. Effects of age on validity of self-reported height, weight, and body mass index: findings from the Third National Health and Nutrition Examination Survey, 1988-1994. J Am Diet Assoc. 2011;101(1):28-34. doi: http://dx.doi. org/10.1016/S0002-8223(01)00008-6.

48. Coqueiro RS, Borges LJ, Araújo VC, et al. Medidas auto-referidas são válidas para avaliação do estado nutricional na população brasileira? Rev Bras Cineantrop Desempenho Hum. 2009;11(1):113-9. doi: http:// dx.doi.org/10.5007/1980-0037.2009v11n1p112.

49. Lucca A, Moura EC. Validity and reliability of self-reported weight, height and body mass index from telephone interviews. Cad Saúde Pública. 2010;26(1):110-22. doi: http://dx.doi.org/10.1590/ S0102-311X2010000100012.

50. Conde WL, Oliveira DR, Borges CA, et al. Consistência entre medidas antropométricas em inquéritos nacionais. Rev Saúde Pública. 2013;47(1):69-76. doi: http://dx.doi. org/10.1590/S0034-89102013000100010.

51. Craig BM. Adams AK. Accuracy of body mass index categories based on self-reported height and weight among women in the United States. Materm Child Health J. 2009;13(4):489-96. doi: http://dx.doi. org/10.1007/s10995-008-0384-7.

52. Silveira EA, Araújo CL, Gigante DP, et al. Validação do peso e altura referidos para o diagnóstico do estado nutricional em uma população de adultos no Sul do Brasil. Cad Saúde Pública. 2005;21(1):235-45. doi: http:// dx.doi.org/10.1590/S0102-311X2005000100026.

53. Dekkers JC, van Wier MF, Hendriksen IJ, et al. Accuracy of self-reported body weight, height and waist circumference in a Dutch overweight working population. BMC Med Res Methodol. 2008;8:69. doi: http://dx.doi.org/0.1186/1471-2288-8-69.

54. Associação Brasileira para o Estudo da Obesidade e da Síndrome Metabólica. Diretrizes brasileiras de obesidade. 4 ed. São Paulo: ABESO; 2016.

55. Goldhirsch A, Ingle JN, Gelber RD, et al. Thresholds for therapies: highlights of the St Gallen International Expert Consensus on the primary therapy of early breast cancer 2009. Ann Oncol. 2009;20(8):1319-29. doi: http://dx.doi.org/10.1093/annonc/mdp322.
56. Goldhirsch A, Wood WC, Coates AS, et al. Strategies for subtypes--dealing with the diversity of breast cancer: highlights of the St. Gallen International Expert Consensus on the Primary Therapy of Early Breast Cancer 2011. Ann Oncol. 2011;22(8):1736-47. doi: http://dx.doi.org/10.1093/annonc/mdr304.

57. Goldhirsch A, Winer EP, Coates AS, et al. Personalizing the treatment of women with early breast cancer: highlights of the St Gallen International Expert Consensus on the Primary Therapy of Early Breast Cancer 2013. Ann Oncol. 2013;24(9):2206-23. doi: http://dx.doi.org/10.1093/annonc/mdt303.

58. Prat A, Perou CM. Deconstructing the molecular portraits of breast cancer. Mol Oncol. 2011;5(1):5-23. doi: http://dx.doi.org/10.1016/j.molonc.2010.11.003.

59. Yersal O, Barutca S. Biological subtypes of breast cancer: Prognostic and therapeutic Implications. World J Clin Oncol. 2014;5(3):412-24. doi: http://dx.doi. org/10.5306/wjco.v5.i3.412.

60. Tafe LJ, Tsongalis GJ. The human epidermal growth factor receptor 2 (HER-2). Clin Chem Lab Med. 2012;50(1):23-30. doi: https://doi.org/10.1515/ cclm.2011.707.

61. Ferrero-Pous M, Hacène K, Bouchet C, et al. Relationship between c-erB- 2 and other tumor characteristics in breast cancer prognosis. Clin Cancer Res. 2000;6(12):4745-54.

62. Voduc KD, Cheang MC, Tyldesley S, et al. Breast cancer subtypes and the risk of local and regional relapse. J Clin Oncol. 2010;28(10):1684-91. doi: https://doi. org/10.1200/JCO.2009.24.9284.

63. Onitilo AA, Engel JM, Greenlee RT, et al. Breast cancer subtypes based on ER/PR and Her2 expression: comparison of clinicopathologic features and survival. Clin Med Res. 2009;7(1-2):4-13. doi: https://doi. org/10.3121/cmr.2009.825.

64. Perou CM. Molecular stratification of triple-negative breast cancers. Oncologist. 2010;15(Suppl 5):39-48. doi: https://doi.org/10.1634/theoncologist.2010-S5-39.

65. Foulkes WD, Smith IE, Reis-Filho JS. Triple-negative breast cancer. N Engl J Med. 2010;363(20):1938-48. doi: https://doi.org/10.1056/NEJMra1001389.

66. Phipps AI, Chlebowski RT, Prentice R, et al. Body size, physical activity, and risk of triple-negative and estrogen receptor-positive breast cancer. Cancer Epidemiol Biomarkers Prev. 2011;20(3):454-63. doi: https://doi. org/10.1158/1055-9965.EPI-10-0974.

67. Calle EE, Rodriguez C, Walker-Thurmond K, et al. Overweight, obesity, and mortality from cancer in a prospectively studied cohort of U.S. adults. N Engl J Med. 2003;348(17):1625-38. 1. doi: https://doi. org/0.1056/NEJMoa021423.

68. Lorincz AM, Sukumar S. Molecular links between obesity and breast cancer. Endocr Relat Cancer. 2006;13(2):27992. doi: https://doi.org/10.1677/erc.1.00729. 
69. Lukanova A, Lundin E, Toniolo P, et al. Circulating levels of insulin-like growth factor-I and risk of ovarian cancer. Int J Cancer. 2002;101(6):549-54. doi: https:// doi.org/10.1002/ijc.10613.

70. Allen NE, Appleby PN, Kaaks R, et al. Lifestyle determinants of serum insulin-like growth-factor-I (IGF-I), C-peptide and hormone binding protein levels in British women. Cancer Causes Control. 2003;14(1):6574. doi: https://doi.org/10.1023/A:1022518321634.

71. Prieto-Hontoria PL, Pérez-Matute P, Fernández-Galilea $\mathrm{M}$, et al. Role of obesity-associated dysfunctional adipose tissue in cancer: a molecular nutrition approach. Biochim Biophys Acta. 2011;1807(6):664-78. doi: https://doi. org/10.1016/j.bbabio.2010.11.004.

72. Ishikawa M, Kitayama J, Nagawa H. Enhanced expression of leptin and leptin receptor (OB-R) in human breast cancer. Clin Cancer Res. 2004;10(13):4325-31. doi: https://doi.org/10.1158/1078-0432.CCR-03-0749.

73. Harris HR, Tworoger SS, Hankinson SE, et al. Plasma leptin levels and risk of breast cancer in premenopausal women. Cancer Prev Res. 2011;4(9):1449-56. doi: https://doi.org/10.1158/1940-6207.CAPR-11-0125.

74. Park H, Kim M, Kwon GT, et al. A high-fat diet increases angiogenesis, solid tumor growth, and lung metastasis of CT26 colon cancer cells in obesity-resistant BALB/c mice. Mol Carcinog. 2012;51(11):869-80. doi: https:// doi.org/10.1002/mc.20856.

75. Ceschi M, Gutzwiller F, Moch H, et al. Epidemiology and pathophysiology of obesity as cause of cancer. Swiss Med Wkly. 2007;137(3-4):50-6. doi: https://doi. org/2007/03/smw-11435.

76. Costa JV, Duarte JS. Tecido adiposo e adipocinas. Acta Med Port. 2006;19(3):251-56.

77. Cleary MP, Grossmann ME. Minireview: obesity and breast cancer: the estrogen connection. Endocrinology. 2009;150(6):2537-42. doi: https://doi.org/10.1210/ en.2009-0070.

78. Osório-Costa F, Rocha GZ, Dias MM, et al. Epidemiological and molecular mechanisms aspects linking obesity and cancer. Arq Bras Endocrinol Metab. 2009; 53(2):213-26. doi: http://dx.doi.org/10.1590/ S0004-27302009000200013.

79. Key TJ, Appleby PN, Reeves GK, et al. Body mass index, serum sex hormones, and breast cancer risk in postmenopausal women. J Natl Cancer Inst. 2003;95(16):1218-26. doi: http://dx.doi.org/10.1093/ jnci/djg022.

80. McTiernan A, Rajan KB, Tworoger SS, et al. Adiposity and sex hormones in postmenopausal breast cancer survivors. J Clin Oncol. 2003;21(10):1961-6. doi: http:// dx.doi.org/10.1200/JCO.2003.07.057.

81. Machado KK, Katz A, Buyse M, et al. Sobrevida global e outros desfechos clínicos em câncer de mama: situação atual e controvérsias. Rev Assoc Med Bras.
2010;56(5):514-16. doi: http://dx.doi.org/10.1590/ S0104-42302010000500008.

82. Agência Nacional de Vigilância Sanitária. Guia para desfechos para estudos clínicos de medicamentos oncológicos. Brasília, DF:ANVISA; 2015. (Guia, n.3).

Recebido em 24/1/2019 Aprovado em 12/6/2019 